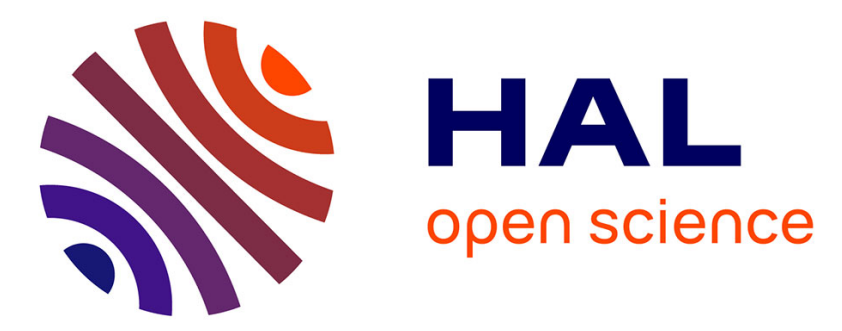

\title{
Design-based research: case of a teaching sequence on mechanics
}

\author{
Andrée Tiberghien, Jacques Vince, Pierre Gaidioz
}

\section{To cite this version:}

Andrée Tiberghien, Jacques Vince, Pierre Gaidioz. Design-based research: case of a teaching sequence on mechanics. International Journal of Science Education, 2009, 31 (17), pp.2275-2314. 10.1080/09500690902874894 . hal-00529922

\section{HAL Id: hal-00529922 \\ https://hal.science/hal-00529922}

Submitted on 27 Oct 2010

HAL is a multi-disciplinary open access archive for the deposit and dissemination of scientific research documents, whether they are published or not. The documents may come from teaching and research institutions in France or abroad, or from public or private research centers.
L'archive ouverte pluridisciplinaire HAL, est destinée au dépôt et à la diffusion de documents scientifiques de niveau recherche, publiés ou non, émanant des établissements d'enseignement et de recherche français ou étrangers, des laboratoires publics ou privés. 


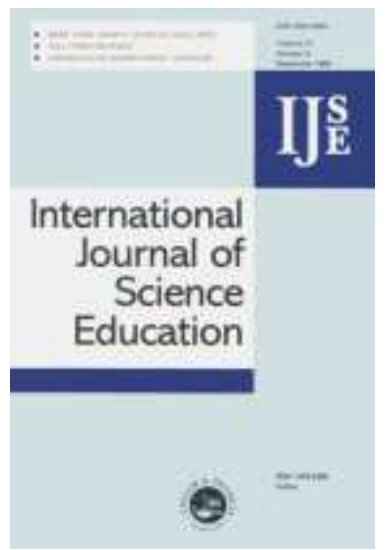

Design-based research: case of a teaching sequence on mechanics

\begin{tabular}{|r|l|}
\hline Journal: & International Journal of Science Education \\
\hline Manuscript ID: & TSED-2008-0158.R1 \\
\hline Manuscript Type: & Research Paper \\
\hline Keywords: & $\begin{array}{l}\text { classroom, curriculum, design study, inquiry-based teaching, } \\
\text { science education }\end{array}$ \\
\hline Keywords (user): & modelling, theoretical approach, teaching sequence \\
\hline \multicolumn{2}{|l}{} \\
\hline
\end{tabular}

\section{S) ScholaroNE \\ Manuscript Central}




\title{
Design-based research: case of a teaching sequence on mechanics
}

\begin{abstract}
Design-based research, and particularly its theoretical status, is a subject of debate in the science education community. In the first part of this paper, a theoretical framework drawn up to develop design-based research will be presented. This framework is mainly based on epistemological analysis of physics modelling, learning and teaching hypotheses. It includes grand theories, a specific theory that following Cobb \& al. (2003) is a 'humble theory' in the sense that it does 'real work', and tools for design. In the second part, we will show how this specific theory and its tools led designers to develop teaching resources in the case of a teaching sequence on mechanics (grade 10). We will explain how the components of the specific theory and tools guide the design at different levels; the conceptual structure of the teaching sequence, the chronology of the activities, the various choices of the type of activity and their wording. This presentation makes the bases of designing teaching resources explicit and therefore allows for scientific debate.
\end{abstract}




\section{Introduction}

Design-based research is an object of debate in the science education community. An issue of the International Journal of Science Education was devoted to this question (Méheut \& Psillos, 2004, invited editors). In their editorial these authors underlined the emergence of this type of research with particular difficulty in making explicit the assumptions and decisions often implicit in the design of teaching sequences and, more widely, teaching materials. They think that:

"it may be due to craft knowledge involved in the teaching and handling of specific content, or to a lack of widely accepted tools for representing teaching; a situation that warrants further study" (p.516) [our italics].

This difficulty is also discussed in an issue of the Educational Researcher (January-February 2003), particularly the theoretical research status of such studies. The article introducing this issue signed by "the design-based research collective" suggests that proper design-based research enhances some characteristics as follows:

“...Research on designs must lead to sharable theories that help communicate relevant implications to practitioners and other educational designers" (p.1) [our italics].

And in the same issue, Cobb, Confrey, diSessa, Lehrer \& Schouble (2003) characterized the status of the theoretical component of such studies by their role: "they are accountable to the activity of design. The theory must do real work" (p.10) [our italics] and consider that the general philosophical orientations like constructivism "often fail to provide detailed guidance in organising instruction" (p.10).

The distance between general orientation or grand theory and designed teaching materials is large; so it is not surprising that diSessa (2006) notes that different grand theories "often 
advocate similar instructional strategies. [...] The use of instructional analogies, metaphors, and visual models is widespread and not theory-distinctive" (p. 276).

It seems necessary to distinguish between general philosophical grand theories and the theories that do real work. The "real work" to design teaching sequences is diverse, there is a variety of decisions to be made relating to the specific teaching content, to the structure of its main aspects, to the order in which they are introduced, to the instructional strategies, and so on (Lopes, Silva, Cravino, Costa, Marques, \& Campos, 2008). In particular, the type of classroom activity, the respective roles of the teacher and students, the teaching resources, the various possibilities of class organisation, the approximate duration of each activity, etc, should be decided according to the specific content to be introduced. Therefore the theoretical framework that does real work should include a variety of theoretical components.

In this paper, the status of the different components of a theoretical framework for designbased research in teaching sequences and their role in the design are discussed in relation to a specific case: the design of a teaching sequence in mechanics for the first year of upper secondary school (grade 10) in France. Then this paper aims to present a theoretical contribution to the field of science education design; it contributes more specifically to constructing a theoretical background for designing teaching resources. This theoretical contribution has emerged from considerable experience of designing teaching resources (more than ten years). This design activity was initially based on teachers' and researchers' experience. This means that the research results and methods known by the researchers were proposed and used by them to contribute to the design. The design was therefore not carried out in the perspective of testing a theory but of ensuring that research serves the design of teaching resources and more generally contributes to improving science teaching. The theoretical proposal presented in this paper has emerged from this design experience in interaction with the evolution of research studies and new research trends on design. 
Following Bannan-Ritland \&Baek (2008), this proposal can be called an "emergent theory" (p. 301).

\section{Theoretical framework leading to theories that do real work in designing teaching sequences}

As proposed by Cobb, the designers, who, as researchers, aim to make their choices and productions explicit and debatable, have to construct specific theoretical elements and, in some cases, specific tools that are directly operational. However, these specific constructions depend on grand theories that can come from several disciplinary fields. To present the way to go from the grand theories to teaching resources we start from the didactic triangle as presented in Figure 1a. Most of the grand theories involved in the design of teaching resources emphasize one of the three poles of the didactical (or pedagogical) triangle; knowledge, learning and teaching, without ignoring the others. We use 'learning' and 'teaching' instead of 'student' and 'teacher' to remain as close as possible to a theoretical approach. These grand theories cannot do real work; specific theories become necessary to design teaching resources. At present such theories are constructed by researchers in science education and are not currently shared by the community. This leads to our first research question dealing with the construction of specific theories from the grand theories to design teaching sequences (Figure 1a). What are the grand theories chosen? How do they contribute to a specific theory? Does a specific theory come from several grand theories? Our second question follows the first one in the design process; it deals with the way in which the specific theories "do real work" to design teaching sequences. More specifically, on what components of the teaching sequence do the specific theories do real work directly? Do they need specific tools to be operational?

For each pole, we will present in turn the grand theories and the specific theories and choices. 


\section{Insert figures $1 \mathrm{a}$ and $1 \mathrm{~b}$ about here}

\section{Knowledge: Grand theories}

The grand theories mainly related to the knowledge pole deal with two fields: sociology and epistemology of knowledge.

\section{Sociology of knowledge: the grand theory of ecology of knowledge}

This grand theory deals with the relations between the educational system, the scientific community and everyday society. Its perspective involves a political level where the objectives of education are defined. But even at the design level where the official curriculum is defined, this sociological perspective plays a role in the designers' interpretation of the curriculum and then on the way they implement it.

In this theory (Chevallard, 1991) there are social conditions for knowledge to exist; knowledge can only stay alive if it is studied and/or used, if not it dies ${ }^{1}$. Here knowledge takes a broad meaning, it is not only declarative knowledge but also the processes of its elaboration and it includes skills. Chevallard (1991) states that knowledge is alive in a group and that the meaning of knowledge depends on the group. For example, energy conservation does not have the same meaning in a high-energy research group as in an ecology group or in a physics classroom in an upper secondary school. He also makes a distinction between the types of

\footnotetext{
${ }^{1}$ This perspective is currently shared among people involved in sustainable archives: to be sustainable, an archive should live; that is, stay available and be used.
} 
relationships to knowledge that a group of people has: production, use, etc. (a researcher and an engineer do not have the same relationships to knowledge) and he analyses the migration of a part of knowledge from a group towards another. This migration is called transposition; it implies necessarily that the meaning of the part of knowledge that migrates will change since it is alive in different groups of people. Didactical transposition consists of the migration of knowledge in the community of reference, called the reference knowledge, towards the knowledge that is alive in the classroom and is called taught knowledge. In physics teaching at upper secondary school, the reference knowledge is the physics knowledge. However, in the case of scientific literacy, several communities of reference can be involved; the scientific communities and the society at the level of a region or country. This allows the designers to introduce social questions such as those raised by the environment. This transposition includes two main steps (Figure 2): (1) from the reference knowledge to the knowledge to be taught, and (2) from the knowledge to be taught to the taught knowledge. The knowledge to be taught can be found in a community of policy makers, teacher trainers and teachers; it mainly consists of official curricula, textbooks or similar materials. This knowledge is usually written for people who are familiar with the knowledge to be taught. The texts are meant for teachers who are specialists of the discipline to be taught. Taught knowledge lives in a classroom and is necessarily associated with a particular class. The class is considered as a system where taught knowledge is a joint production of the teacher and the students and is therefore specific to a classroom (Mercier, Schauber-Leoni \& Sensevy, 2002). Let us note that this way of considering a classroom is related to the teaching pole.

[Insert figure 2 about here] 


\section{Epistemology of knowledge: modelling}

Here the epistemology concerns not only disciplinary knowledge but also everyday knowledge. The reason for this comes from the grand theory of learning that we have chosen; socio-constructivism. From this grand theory, the students' initial knowledge plays a major role in learning; it is therefore important to better understand how everyday knowledge works. Thus our epistemological choice is also related to the learning pole (Figure 1b).

All the teaching sequences designed in our group have the same epistemological grand theory (Figure $1 \mathrm{~b}$ ). We have chosen to favour the basic processing of physics: modelling. In the following we will introduce our epistemological view on modelling in physics and in everyday situations.

\section{View of modelling in physics}

Let us note that this analysis is carried out in order to be used as a reference in the transposition process from scientific knowledge to taught knowledge and not to study experimental science in itself. Our choice is based on the works of several epistemologists (Bunge, 1973; Bachelard, 1979; Giere, 1988) who have considered that modelling of the 
material world is at the heart of physics. To characterize this process we will refer to Hacking (1983/2005). We retain the following main points:

- Theories are not easy to define; analysing the Faraday effect, Hacking shows that "at least six different levels of theory" (ibid, p.212) are involved. For him "theories cover lots of productions" (p.212). For example physicists can use different theories, more or less mathematical, to interpret the same facts.

- Observations are not necessarily driven by physics theory. There have been important observations in the history of science that have included no theoretical assumptions. We share Hacking's view in the following statement:

"Now of course Bartholin, Grimaldi, Hooke and Newton were not mindless empiricists without an 'idea' in their heads. They saw what they saw because they were curious, inquisitive, reflective people. They were attempting to form theories. But in all these cases it is clear that the observations preceded any formulation of theory." (ibid, p.156)

Let us notice that this position is neither the positivist one nor that of philosophers like Lakatos, Feyerabend who, even though their opinions may differ, "were saying that there are no purely observation statements because they are all infected by theory" (ibid, p.171). Hacking insists on the idea that observation and experimentation cannot be replaced by linguistic entities (observation sentences). For us, this aspect is important for the transposition from this scientific community level to the secondary teaching level.

- Theory and experiments cannot be directly articulated. Hacking has proposed two main reasons for this:

"Most initial speculations [theories] hardly mesh with the world at all. This is for two reasons. One is that one can seldom directly deduce from a speculation 
consequences that are even in principle testable. The other is that even a proposition which is in principle testable is often not testable, simply because no one knows how to conduct the test. New experimental ideas and new kinds of technology are required." Then there is "an enormously wide-ranging intermediary activity best called model-building." (p.216)

- The same idea of the difficulty of articulation is also reinforced by the analyses of Bachelard (1979) and Hacking (1983/2005), who consider that there are two processes in model building: a process from the theory, which makes the theory more concrete or visible and a process from the experiment, which makes the experiment more abstract. In this epistemological analysis we will call a 'model' the result of this double process (the word 'model' will be used with a different meaning in the design activity we present below) and 'modelling' this double process (with the same meaning in the design activity). The model is an intermediary between theory and experiment. It can be considered as having two facets, one from the theory and the other from the experiment. Let us note that this double modelling process, according to the scientists and/or the time period, is not unique; it can lead to different models.

\section{View of modelling in everyday situations}

Our grand theory on learning (socio-constructivist with Vygotski, figure 1b), as we discuss below, has led us to analyse the distance between physics modelling and the processes involved in everyday knowledge. To assess this distance we will also analyse everyday knowledge in terms of modelling.

Epistemologists have studied physics cognition for several centuries but they have not studied everyday cognition. Various disciplines have approached this field, in particular anthropology, cognitive science, ethnology, linguistics, psychology and science education. We do not claim to review all the existing works; we will just provide some of the main 
elements that have led us to draw up our theoretical framework. Let us first note that everyday knowledge is not commonly recognized as knowledge that could be an object of study in itself; there are no epistemologists of everyday knowledge, or very few. It is more often aimed at understanding how people live and how they speak, think, etc. We will consider five main aspects:

- Categorisation is a fundamental component of interpretation of the material world. Psychologists have studied this thinking process as well as anthropologists and ethnologists such Levy-Strauss (1962).

- Causality is also a fundamental component of explaining the material world. Piaget and, more recently, researchers in cognitive science and science education have studied causality (Piaget \& Garcia, 1971; Tiberghien, 2004; Saxe \& Carey, 2006).

- From birth, individuals construct their own knowledge of the material world before even language acquisition (Spelke, Phillips \& Woodward, 1995). As in the case of observation in physics, we will consider that perception plays a major role. Communication and language also play a major part in the construction of knowledge of the material world; the richness of everyday language, particularly with its metaphors and the polysemy of words, helps this understanding. Then there is also a cultural transmission of this knowledge.

- Our understanding of the material world includes some general approaches such as categorisation and causality and more specific components that form a kind of set of theories (Vosniadou \& Brewer, 1992). In this matter we do not share diSessa's approach of "knowledge in pieces" (2006), even though we widely acknowledge the interest excited by P-prime. This set of theories is individual and collective as part of a shared culture, particularly when involved in a common language. 
- In everyday knowledge the questions that are raised about the material world, including artefacts, are driven mainly by our uses and do not aim at understanding the world as in physics. Everyday language is very rich, particularly with the polysemy of words.

Our analysis leads us to consider that modelling processes are involved in everyday knowledge. They involve a set of knowledge elements that we call theories in the sense that they allow people to explain a large variety of behaviours of the material word (objects and events). This set includes general approaches like causality, categorisation and more specific elements of knowledge that can deal with local behaviours of the material world. We are well aware that using the word "theory" is a radical choice; it does not mean that these theories are similar to the theories in physics, they merely play a similar role in the explanation of a large part of the material world involved in everyday situations. Moreover there is a wide difference in the modelling process, whereas in physics the relations between theories and experiments are not at all direct as we have shown above. In everyday knowledge the "theoretical elements" can very often be related directly to the behaviour of the material world.

\section{Knowledge: Specific theory of the two worlds}

From our grand theories on modelling in physics and in everyday knowledge, we have worked out a theoretical framework in order to use it when designing teaching sequences. We will present this framework firstly for physics knowledge at school, then for everyday knowledge. To do this, we take into account the relationship between knowledge and the two poles learning and teaching (Figure 1b). 


\section{The two worlds of physics knowledge to be taught}

In the transposition process we will keep to the elementary physics that is taught until the first year of university. In this case, there is macroscopic physics in which objects and events are almost directly observable because they are investigated with rather simple instrumentation. There is also microscopic physics in which particles associated with events are not directly observable; in this case the objects (particles) and events have to be constructed as belonging to the material world with the intermediary of simulation in some cases. The cases in which the experimental field is studied with complex instrumentation, for example studies of particles (high energies, etc) are not considered.

The main point for us is that, even in the case of elementary physics, the relation between theory and experimentation is not direct at all and includes several modelling processes. Then the question is raised of how to deal with the model, which is an intermediary between theory and experiment (Hacking, 1983/2005; Bachelard, 1979). In this intermediary role, let us consider how to transpose the process going from theory to experiments and the reverse (see the left part of Figure 3). When analysing the usual physics teaching content, the theory is not differentiated from the model, particularly from the components of the model that come from the theory.

\section{[Insert figure 3 about here]}

In the case of mechanics, for example, Figure 4 presents a short extract from a text given to the students with the status of theory in the case of the teaching sequence on mechanics. This text, associated with formal language (vector in this case), presents Newton's third law in natural language, and also introduces the rules to represent a force vector. The text presenting Newton's law is part of the theory (lines 1 and 8), but the second part of the text on the force is not strictly theory; this second part presents the modelling process that comes from the 
[Insert figure 4 about here]

theory and helps to construct a model from measurements and observations of a material situation. The two sentences: (1) line 6: "length is proportional to the value of force" or (2) line 9: "The vectors which represent forces are on the same straight line; this straight line depends on the situation being studied" introduce "slots" to be filled by the results of measurement of the force or the observation of a straight line.

Regarding the material world, we have chosen to bring together observation and experimentation. The main reason for this is that both provide information on the behaviour of the material world depending on the conditions of experimentation or observation. This statement is relevant because of the rather elementary physics level of secondary school as discussed above. Concerning the modelling process starting from experimentation or observation, our position is the following: event and measurement readings (thermometer, ruler, voltmeter, etc.) belong to the material world in the sense that information is picked up by perception (any modality). On the other hand, as soon as the values of the measurement are involved in treatment, we consider that they are intermediaries and close to the theory/model part; in fact they are on the facet of the model dealing with the experimentation/observation side.

We obtain five components of modelling, among them two (2 and 3) deal with actions of modelling (left part of Figure 3):

1) Theoretical physics statements / Relation between physics concepts

2) Selecting and processing the theoretical elements that fit the selected events and measurements 
3) Model built from the components 3 and 4

4) Selecting and treating events and measuring

5) Observation of and experimenting on objects and events

At secondary school level, we consider that modelling consists of going back and forth between these components: the order given does not mean that modelling implies all components or that only successive components can be related; all relations are possible. Based on different research studies, in particular those who studied the learning pathway (introduced by Scott, 1992) along a teaching sequence (Tiberghien, 1980; Niedderer \& al., 2007; Clement et Rea-Raminez,. 2008), we considered that to give a physics meaning to theoretical statements and to observation / experimentation, it is necessary to distinguish between them and to relate them. In physics teaching, the relations are often between the observations of the selected events and/or the actions of measurements on one hand and their formal treatments on the other hand (Tiberghien \& al. 2001). These two components are not the aim of modelling; they are a way to relate theory and observation in order to understand physics.

This analysis leads us to group the four components into two sets: one, the world of objects and events, including observations and measurements which, due to the physics teaching level, can be done directly; and two, the world of theories and models which involve theoretical statements and modelling components, including treatments of measurements and/or of selected events.

At the beginning of our work on transposition of modelling, we wanted as researchers to make a distinction between theory and model. However, the teachers working with us in the design thought that it would be too difficult for the students and even for the teachers who do not participate in the design; then we rapidly chose the two worlds (Figure 3). 
The world "theories and models" includes theory and modelling elements, allowing us to relate theory to the observed and selected event or measurement readings as in the example presented in Figure 4. The world "objects and events" includes the material (inanimate) world and the observation and description of objects and events including measurement readings.

\section{The two worlds of everyday knowledge}

Our analysis of everyday knowledge allows us to structure this knowledge in two similar sets to match with physics modelling in order to better understand the distance between the physics to be taught and everyday knowledge. We consider that in everyday life, explanations or interpretations of material situations are guided by ideas with some general common approach like categorisation and causality and more local theories associated to specific sets of situations such as the well-known student conceptions in mechanics; for example, considering a force (like power) to be necessary to a motion (Viennot, 1996), a conception which is related to causality, whereas another conception that "the Earth is flat" is related to categorisation. We therefore lay down the hypothesis that, in everyday life, there is also a modelling activity of the material world. This means that when a person or group explains or interprets the material world or makes a prediction, a modelling activity is involved (Tiberghien, 2000). This hypothesis can be related to mental models in cognitive activity whatever the type of knowledge involved (Gentner \& Stevens, 1983). Clement and his colleagues have widely developed this perspective in science teaching (see the recent publication: 2008). In our theoretical framework we emphasize that modelling activity involves explanatory ideas that we associate with a theoretical level on the one hand and with observation, perception and possible measurement (such as ambient temperature) of objects and events on the other hand. This leads us to a similar structure to that involved in physics knowledge at school. This similarity of structure should not hide the fact that in everyday knowledge the relations between explanatory ideas (equivalent to physics theory) and objects 
and events are almost straightforward. There is therefore a huge difference between everyday and physics knowledge.

In conclusion, we obtain a double categorization of knowledge: everyday and physics knowledge, and for each of these categories, theories/models and descriptions/observations in terms of objects and events of a material situation are distinguished (Figure 5); obviously an element of knowledge belongs to a given category depending on the context of use. In particular, a notion like "action" (used in the text of Figure 4) is firstly a concept of the teaching sequence because the students have to conceptualize the contact between two objects as the idea that an object acts upon another, called "action". Then secondly, when the students are familiar with this "view" of material situations, the notion of action can be considered as describing a type of fact.

We are well aware that the words 'theory' and 'model' are used in relation to everyday knowledge with a broader meaning than in physics.

[Insert figure 5 about here]

In Figure 5, six bidirectional arrows show the multiple relations between the different types of knowledge that can be used for designing teaching sequences. Students can establish relationships between their everyday descriptions of objects/events and theoretical elements of physics knowledge that have been learnt. Students can also identify relationships between their everyday theories about the behaviour of the material world and some elements of the physics theory that are presented during teaching sessions. This specific theory of the "Two Worlds' is further developed with our specific choices on learning (next paragraph). 
In the cases of school-taught physics or everyday life, relying on modelling to analyse different types of knowledge processing is a theoretical choice which entails methodological consequences. It leads the researcher to separate knowledge into two main categories: theories and models on the one hand and objects and events on the other hand.

\section{Learning: grand theory and specific choices}

Socio-constructivism has been chosen as the grand theory (Vygotski 1934/1997) (Figure 1b). Starting from socio-constructivism, we have emphasized the dynamics between the two interand intra-psychological plans:

"Any function in the child's cultural development appears twice, or on two planes. First it appears on the social plane, and then on the psychological plane. First it appears between people as an inter-psychological category, and then within the child as an intra-psychological category" (Vygotsky cited by Wertsch (1985) p. 60).

For us the classroom allows students to construct meaning on a social plane where the cultural development can take place. The students' cultural development is favoured by the mediation of language and other people, particularly the teacher and other students.

The proximal development distance is another aspect of the Vygotskian theory that we have emphasized. This aspect can also be related to Piagetian constructivism, on which many studies of student conceptions have been based.

Our position on learning has been reinforced with a series of research studies in science and mathematics education. We have focused on studies relating to students' learning in the classroom during a teaching sequence. These studies deal with the individual student's learning pathway (Psillos \& Kariotogou, 1999, Küçuközer, 2000, 2005; Givry, 2003; Givry and Roth, 2006). From these results, we deduce that this pathway follows neither a rational decomposition of disciplinary knowledge nor the order of introduction of taught knowledge in 
the classroom. The pathway towards understanding the relationships between concepts does not necessarily start by understanding each concept; the learner's construction of his/her own understanding may involve simultaneously this relationship and each one of its terms. Moreover, most of the time students, at the end of the teaching sequence, construct intermediary knowledge between initial and target knowledge.

Insert figure 6 about here

The students' construction of knowledge during a teaching sequence can be well interpreted if the analysis of the classroom and students' discourse is done at several granularities of knowledge, including a micro level (Tiberghien and Malkoun, 2007). As illustrated in Figure 6, learning can consist of relating an element of knowledge involved in the taught knowledge to a set of elements of knowledge already acquired, that is not necessarily the set in which this element has been inserted in the taught knowledge. Therefore the meaning of an element of knowledge constructed by a student can be different from that in the taught knowledge. We set down the following position on learning: constructing the understanding of a concept or notion requires establishing new relations between elements of knowledge; these elements can be "small". The relations constructed by students between small elements of knowledge can be different from those involved in the taught knowledge and students can therefore acquire elements of the taught knowledge without an overall conceptual understanding.

This position on knowledge is compatible with several grand theories and particularly with our choice of socio-constructivism. It only supposes the importance of prior knowledge. It also, but more implicitly, supposes the importance of the situation in which the knowledge is introduced because the learner constructs relations between a new element of knowledge and his/her prior elements of knowledge according to his/her overall understanding of the 
situation. Consequently, a teaching sequence should give students the opportunity to "tune" their understanding of a new element of knowledge better, owing to the possibility of re-using it in successive classroom activities. This position emphasizes the role of small elements of knowledge, even if they are included in a general approach like when a teacher introduces new laws or experiments. This position therefore has consequences because it becomes necessary when designing teaching sequences to pay particular attention at the fine level of knowledge granularity.

\section{Teaching: theories of didactical situations and joint actions}

The French theory of didactical situations (Brousseau, 1998) considers the classroom as a system which is characterized by several concepts. This theory has been further developed by Mercier, Schubauer-Leoni \& Sensevy (2002) and Sensevy (2007). In this theory the classroom is viewed as a community of practice involving two simultaneous actions: teaching and learning. Therefore in a classroom the teacher and the students co-construct the taught knowledge; they act together.

We will limit ourselves to the two main concepts of this theory that we have used in our framework.

Chronogenesis accounts for the evolution of knowledge during teaching. In the classroom perspective, this evolution takes place over an academic year. Let us note that chronogenesis can also be used to study the evolution of the curriculum for a given discipline such as physics along the whole schooling process. Chronogenesis is not limited to a particular time scale.

The didactical contract introduced by Brousseau (1998) meets with the reciprocal expectations that the teacher and the students may have. It forms a system of norms, some of which are generic and will be lasting, and others are specific to elements of knowledge and 
need to be redefined with the introduction of new elements. For example, after the teacher has introduced the concept of force, his/her expectations of the students' interpretations of material situations will be different from before.

The concept of didactical contract is close to what Cobb et al. (in press) call normative identity:

"The two central constructs of the analytic approach that we propose are the normative identity as a doer of mathematics that is established in the classroom, and the personal identities that individual students develop as they participate in classroom activities. [...]." (Cobb, in press) (our italics).

As in the concept of didactical contract, normative identity refers to class phenomena, whereas personal identity refers to an individual in a community.

In this study we have not developed a specific theory for teaching itself but we have made a clear choice which we draw directly from the concept of didactical contract and which deals with classroom management and the role played by students' proposals. These proposals, whether or not they are right, are considered as potentially relevant and can be publicly presented and debated in classrooms. This means that the teacher expects answers and justifications for answers from the students and that the students expect to be understood. The teaching activities should therefore allow teachers to let students make their own proposals, write and debate them, and compare them with the physics proposals. Students will then be able to take responsibility for constructing new elements of knowledge. Later on, these elements will have to be institutionalized by the teacher.

Other aspects of teaching design are still a kind of craft knowledge. In the case of our design, we consider the teacher's role as threefold: a mediator, a person in charge of maintaining the 
scientific story and, thirdly, a guide for the development of classroom discussion (DumasCarré \& Weil-Barais, 1998; Mortimer \&Scott, 2000; Leach \& Scott, 2002).

In conclusion, our theoretical framework is particularly developed on the knowledge aspects; relations between learning knowledge and teaching knowledge. It is less developed in relations between learning and teaching, and in particular on aspects dealing with classroom management.

We will now deal with the second question concerning how this theoretical framework may guide the design of a teaching sequence. As we have already mentioned, we will present this guidance in the case of a teaching sequence in mechanics (grade 10). This sequence has been designed using the specific theory of the Two Worlds; however, there has been a strong interaction between designing it and making this theory explicit. Before presenting how the specific theory guides the design, we introduce the social context of this design.

\section{Context of the research development of the sequence in mechanics}

Our research team (ICAR, COAST group) has been working on research development projects for over ten years. These projects have been carried out by groups of one or two researchers with four to six teachers working together to construct teaching sequences based on the official curriculum. A series of sequences on different topics and at several levels (grades 10, 11, 12, and recently 7, 8) have been developed (Gaidioz \& Tiberghien, 2003; Gaidioz, Vince \& Tiberghien, 2004; Le Maréchal et al., 2004a; Le Maréchal, Perrey, Roux, Jean-Marie, 2004b). More specifically, each sequence is designed by a group of researchers and teachers who have met regularly over two or three academic years (weekly or twice a month). Each group participated in creating the sequence and in the first year, each of the designed activities was tested by some of the teachers in the group; then in the second year the teachers of the group used the whole sequence and discussed it during meetings in order to 
modify either a given activity or the order of activities or even the structure of the sequence itself. For some sequences, a PhD student contributed.

We recall that our design activity began with the aim of proposing teaching resources to improve science teaching, particularly to improve students' physics understanding. Our aim was not to test a theory; the theory has emerged from this design activity in interaction with research activity. Therefore testing the teaching resources did not consist of testing a theory and was carried out in complex ways including two main stages. The first stage, called the 'local impact evaluation phase' by Bannan-Ritland \& Baeck (2008), is characterized by iterative refinement processes. The second stage consists of evaluating the impact of a teaching sequence on students' acquisitions. This last stage can only be carried out when the sequence is finalised and used by teachers who did not participate in its design. We do not develop this stage in the present paper; that would necessitate another study. In particular, this evaluation implies a change of scale from a few classes to a larger number of classes. We just mention that, for some of the sequences, questionnaires were given out before and after the sequence in several classes that used the sequence and in a similar number of "ordinary" classes (Tiberghien \& Malkoun, 2007).

The first stage involved two aspects related to teaching and learning, particularly at the level of an activity (or task). The first aspect was focused on the usability and relevance of the teaching resources for the teachers in the classroom; it was central when a group of designers was creating the initial design of the activities to be given to the students in the class. The teachers participating in the group tested the activities in their classrooms, and their feedback played a major role in the improvements. The second aspect concerned the validity of the teaching resources for students' learning. It involved the research studies investigating students' learning in the classroom when the teachers taught these designed activities; it also played a major role in the refinement process. These studies used video data of the classroom. 
For video recording of the classroom, the same two students were in the field of one camera (most of the time two cameras were used in the class; one on a group of students and a part of the class and the other on the teacher and a part of the class or on another group of students). The focus of these research studies was not only the students' understanding of the activities but also the way students were involved in them or, in other words, how these activities allow students to be autonomous and to take the responsibility of knowledge to carry them out. The overall research question of the studies was to better understand the students' learning pathway in relation with teaching. With this orientation, the research results for each designed activity were at a fine granularity level. Even if these studies used a case study methodology and then observed a small number of students, they made in-depth analyses of the role of each activity: the way the statement was formulated, the role of key words, the role of the chosen experiments, etc. These analyses are particularly rich for the design of each activity that is focused on the students' and teachers' possible actions during teaching. Let us note that the relevance of the research studies is all the more important given that the teachers who participated in the group and who tested the designed activities in their own classes cannot analyse such data. Therefore the teachers' experience in the classroom and the researchers' analyses were complementary, providing feedback on the implementation in class. Moreover, the researchers, who were in the classrooms, also contributed by giving feedback on these implementations. During the two or three years after this first phase of elaboration, when the researchers analysed all the data during the whole teaching sequence, the feedback was focused on the students' main difficulties of conceptual understanding, the chronology of the new elements of knowledge introduced in the sequence in relation with the possible learning pathways. The teachers who are more familiar with the sequence also give feedback on difficulties in carrying out specific activities in terms of classroom organization, material constraints or on how to take into account students' ideas in the classroom debates. This 
improvement process can range over several years and is typical of design activity (Lijnse, 2000; Viennot \& Raison, 1999). Let us note that this process is particularly in line with the use of digital dissemination (website) allowing modifications.

More specifically, the SESAMES sequence ${ }^{2}$ on mechanics, grade 10 , discussed in this paper has been involved in different research studies. Küçüközer (2000) first studied students' understanding during teaching as they were students working in small groups and the teacher was a member of the design group. The other studies have dealt with diagnostic evaluation (Coulaud, 2005), the evolution of taught knowledge in two classrooms, one using the SESAMES mechanics teaching sequence and the other using a sequence created by the teacher (both following the official curriculum) (Malkoun, 2007), an evaluation of the mechanics teaching sequences by means of questionnaires before and after teaching in 20 classes (Malkoun, Vince \& Tiberghien, 2007) and, lastly, a study of how a teacher who did not take part in a research development group used the designed sequence for the first time (Jeannin, 2006).

These resources were made available on the official educational website of our area (http://www2.ac-lyon.fr/enseigne/physique/sesames/). A website for teachers called PEGASE (http://pegase.inrp.fr) was also created. These groups of secondary teachers and researchers have been in charge of in-service teachers' professional development for several days every year.

\footnotetext{
${ }^{2}$ From the very beginning, the research development projects have had several names; the current name SESAMES has been used for six years, so we will refer to the mechanics teaching sequence as a SESAMES sequence.
} 


\section{How do specific theories and choices guide the design of teaching content?}

We have presented the structure and content of our theoretical framework; the grand theories, the Two-World specific theory, and the specific choices dealing with knowledge, learning and teaching. Now we will introduce the way in which the design has been carried out. To do this we have constructed two complementary tools. The Knowledge Distance tool guides the framing and sequencing of the teaching content, while the Modelling Relations tool guides the design of specific teaching activities with a finer grain size. Moreover, the need to describe each activity and to involve several representations led us to use research results in the field of multiple representations. Among others, a French researcher (Duval, 1995) has developed a theory on "semiotic registers and intellectual learning". Our tool called "semiotic registers" derives from this theory and is also compatible with others. The tool deals with semiotics and has been called "semiotic registers".

\section{The design tool: knowledge distance}

The tool called "knowledge distance" makes explicit the difference between the knowledge to be taught and students' knowledge as analysed in terms of modelling (Buty, Tiberghien, \& Le Maréchal, 2004). It comes from the Two-World theory and from the grand theory on learning concerning the zone of proximal development.

[Insert table 1 about here]

This tool (Table 1) combines the analyses of students' prior knowledge (everyday and school physics knowledge) and of the knowledge to be taught in terms of modelling. It is well adapted to a granularity of knowledge elements like a notion or concept. We present it in the case of action and force. 
The first column refers to the two worlds and their relations; the second and third columns lead the designers to make their hypotheses on the students' everyday knowledge as well as the already acquired physics knowledge explicit. In the last column, the designers should specify what the students have to learn. In all cases the theoretical components of knowledge and the knowledge related to observation of the material world are differentiated. In the teaching sequence in mechanics, the choice of introducing action and a model of interactions with symbolic representations aims to help students dissociate the overall relationships, particularly the idea that force (like power) is a necessary cause for a motion, called "causality-force", and the idea that associates force and motion, called "force-motion".

\section{The design tool: Modelling relations}

The second tool makes explicit the kinds of relationships that this teaching should lead students to establish. Figure 7 summarises four different kinds of relations between the worlds of theories and models, and objects and events:

1. Relations between objects and events

2. Relations from objects and events to theories and models

3. Relations from theories and models to objects and events

4. Relations between theories and models

According to the specific Two Worlds theory, the designers conceive teaching activities for which students have to construct relationships of types 1,2 and 3 (in two directions between theoretical elements and objects or events), and 4 (Figure 7).

[Insert about here figure 7] 


\section{[Insert about here figure 8]}

The model can be introduced either before the activity, at a specific point during the activity or as a conclusion to the activity; in the latter case, it is involved in the following activity.

\section{The design tool: semiotic registers}

Another way of analysing knowledge is semiotics. The written description of the experimental field and theory in physics and chemistry invariably involves a variety of what Duval (1995) calls semiotic registers: natural language, vector register, algebraic register, drawings and pictures. Duval (1995) stated that different semiotic registers associated with a concept should be used and related to construct its meaning. Figure 8 gives an example of 
these registers: natural language, a diagram (two ellipses and the arrow) representing interaction, and the vectors representing forces in a specific case of interactions between two objects. The role of natural language is essential; it has to be used in the passage between different semiotic registers, such as from schemas to the vectors.

\section{Designing the teaching sequence}

A teaching sequence involves several components, in particular its structure, the didactical organisation, each activity, and the comments for teachers. In this section, we have presented the design process in the case of a teaching sequence on mechanics (grade 10) called a "SESAMES sequence" and we have introduced wider teaching resources for teachers based on our specific Two Worlds theory, choices and tools (Figure 1b).

\section{Didactical organisation}

As shown in Table 2, a major difference between this SESAMES sequence and usual physics teaching is that there is no lecturing to introduce and structure knowledge. New knowledge is introduced through activities that students have to carry out in small groups. For each activity, there is a statement (often a written sheet) and, for some of them, the students are given a model as presented above (examples in Figures 4 and 8). Then, after working in small groups, there is a crucial phase involving classroom discussion about the students' procedures and solutions; during or at the end of this phase, the teacher states the relevant physics knowledge and institutionalises it. This design is related to our specific choice on the didactical contract. This comparison with the current practice is essential in the French context in that it is the practice used by the majority of teachers. Our practice must therefore be explained in comparison to the current one, to enable teachers to understand it. Let us note that our choice is related to the socio-constructivist grand theory. 
[Insert about here Table 2]

\section{Structure of the teaching sequence}

The Two-World specific theory guides the design process of the sequence due to the necessity of differentiating between theoretical elements and objects or events. In the case of the mechanics teaching sequence, this guidance appears when compared with the structure of the official curriculum (Figure 9). The difference is shown in the first rectangles at the bottom (Part I, figure 9).

The official programme introduces force through its effect. It implies that, having a twofold status, force belongs to the world of objects and events since it has observable effects and at the same time it begins to be a physics concept. In the research-based design activity, the distinction between the two worlds has led the designers to introduce the notion of action as a description of what is happening between material objects at the level of objects and events.

\section{[Insert about here Figure 9]}

In the second part (II) of both cases, the concept of interaction was introduced and then the concept of force. However, in the SESAMES sequence, an intermediate model of interaction is explicitly introduced (part II) before introducing force. This intermediate model was added to avoid introducing the effects of force as proposed in the official curriculum. The main event related to the concept of force is the action between objects, even if they are motionless. When two objects $\mathrm{A}$ and $\mathrm{B}$ are in contact, there is an action of $\mathrm{A}$ on $\mathrm{B}$ and of $\mathrm{B}$ on $\mathrm{A}$. Then, as previous research studies suggested (Guillaud, 1998), the event of action is introduced; this is the aim of the intermediary model. This model includes a symbolic representation (diagram in 
Figure 8). Then two elements of knowledge: action between objects (event) and force exerted by a system on another system (model of this event) are clearly distinguished (see Table 1).

For the second part of dynamics concerning Newton's laws, the specificity of the SESAMES sequence is shown in the way laws are formulated, as they include four logical implications between compensation (or not) of forces and the type of motion. For example: "If there is motionless or constant velocity then forces compensate each other" and "If forces compensate each other then there is motionless constant velocity". The development in four logical implications is related to our learning choice that students' understanding can be made easier if elements of knowledge are small. There are two other statements related to change of motion and force. Let us note that according to the official curriculum, acceleration is not introduced and force is related to the velocity change.

\section{Type of activities according to the Two-World specific theory}

As presented before, the case-based research studies give an in-depth analysis for each teaching activity of a group of two students and of the classroom work during correction. The group was analysed during the whole teaching sequence; each activity is not analysed in an isolated way. Furthermore, in the whole class, when the teacher asks the students to present their solution and leads a debate, the students' work and arguments of the observed students are compared to others. The analyses of the two students are therefore situated in the whole class. Moreover, these analyses are proposed to the teachers of the group who can compare them to what happens in their own classes. These results have allowed the researchers to better understand the potential of the activity on two main points: (1) to help students use the elements of knowledge and reasoning that the activity intended them to use, and (2) to allow the whole class to co-construct the new elements of knowledge that the activity is supposed to introduce. Such case studies have only allowed basic hypotheses, but they offer the advantage 
of providing detailed information on the potential of most of the activities that have been designed.

In the following, we will illustrate the relationships (Figure 7) by teaching activities. Relationships 2 and 3 are often both involved in the activities. Most of the time an activity has too large a granularity of knowledge to involve only one of them. This is why we present two activities, one illustrating mainly type 2 relationships and the other illustrating mainy the relationship between the theory/model and the objects/events (types 2 and 3).

\section{Activity about relationships at the objects and events level (type 1)}

This type of activity is not common in ordinary teaching at upper secondary level. Most of the time, teachers consider that such activities are too easy for the students.

\section{Designed teaching activity}

This modelling approach has led the designers to consider that students have to learn how to describe material situations in terms of objects and events in a way which is relevant to physics, since this description is different from descriptions made spontaneously by the students. Particularly in mechanics, motionless situations are described in different terms in everyday life and in physics. Since there is no observable change, interpretation of the motionless situation in everyday life is not interesting. In physics, motionless has to be interpreted in the framework of laws in which motionless and rectilinear motion are similar depending on the frame of reference. As we introduced before, the designers therefore decided to teach how to describe motionless situations with the word 'action' and its associated verb 'to act' (Guillaud, 1998, Küçüközer, 2000). In such a description, these words have a different meaning from the one they have in everyday situations where they imply a change. This activity given in Figure 10 is in part II of the SESAMES sequence (Figure 9). 
In this activity the students are more or less guided to use the verb "to act". This should lead them to conceptualize the situation in terms of action. As we have already mentioned, at this stage, action is a conceptual construction for students, whereas later on, in the sequence and in physics, it will be at the level of objects and events.

Let us note that the choice of an ordinary object like a stone, and not of an object from a physics laboratory like a "weight" used in a Roberval scale, and the choice of the verb "to act" are at a fine level of granularity of knowledge.

\section{[Insert about here Figure 10]}

\section{Example of students' work in class}

As mentioned above, a research study was carried out in a classroom during the design of the sequence, the teacher being a member of the design group. This case study was aimed at studying how the students' understanding evolves during the teaching sequence (Küçüközer, 2000).

Regarding the students' use and understanding of the verb 'to act', different analyses carried out in several classrooms have shown that students tried to use this verb and associate it with a thought experiment; for example, if we cut the elastic string, the stone will fall so the string supports the stone, or they might say sentences like "the earth pushes the stone downwards". This type of activity helps students to associate 'to act' with potential changes and to use it to describe motionless situations even though nothing happens in the situation (which is an important step in learning). This language of description of the material world belongs to physics knowledge. 
366 S2: what are the objects(?) [...]

369 S2: hmmm attraction isn't an object [they laugh]

370 S1: well, the thread $[\ldots]$

$371 \quad$ S2 elastic

372 S1 yeah

373 S2 ah but there are several objects

374 S1: hmmm first there's this [holds the stone], then there's that, the elastic string, then hmmm since there's an 's' [in the activity statement] there are at least two

$[\ldots]$

385 S2: you could say attraction but it's not an object

388 T: $\quad$...the attraction of what(?)

389 S1: of the ground [in French S1 says "terrestre" $]$

$390 \quad$ S3 yes

391 T: why is there this attraction? I'll leave you to think about it

392 S1: because of the stone, the heaviness of the stone

\footnotetext{
${ }^{3}$ In French "attraction terrestre" is an rather current expression; let us note that gravity is also used.
} 


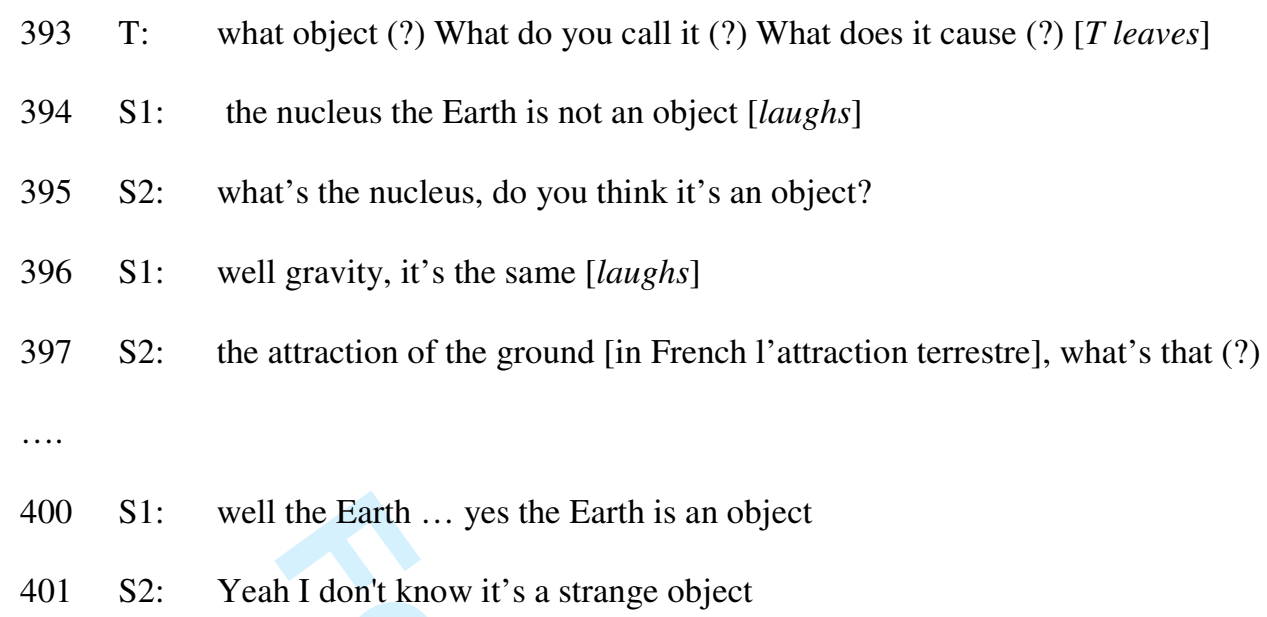

This extract shows the students' difficulties in considering that the Earth is an object just like the stone; finally S1 (400) concludes that it is an object and that attraction and gravity are not (385) which is implicitly confirmed by the teacher, and S2 accepts S1's proposal adding "strange" (401).

In fact this activity requires a specific physics way of "seeing" the material world i.e. putting a small stone and the Earth or any material object in the same category: "object". This has to be learnt by the students. This phase of description, which is often neglected in physics teaching, is necessary to students' understanding of physics (Sensevy \& al., 2008).

Several data on this activity have shown that the students are usually involved in the task and discuss it using elements of knowledge considered as relevant (by the designers). This does not mean that students propose the correct knowledge from the physics point of view. In this sense, the activity allows students to take responsibility for constructing (or starting to construct) new elements of knowledge, particularly a new meaning for "to act" and "action" and a new categorisation of Earth as an object, which for us is confirmation of this activity's potential to improve students' understanding. 
Activities involving relationships from objects and events to theory/model and the reverse (types 2 and 3 )

We first present an activity whose the first question mainly illustrates a type 2 relationship, then another activity which requires using both relationships ( 2 and 3 ) and but mainly type 3 .

\section{Activity about relationships from objects and events to theory/model}

This type of activity is most common in physics teaching (Tiberghien, Veillard, Le Maréchal, Buty, \& Millar, 2001)

\section{Designed teaching activity}

We give an example Figure 11. This activity shows a specificity of SESAMES sequence which asks students to use the text of a model (for example, Figure 8). As we have written before, an activity like this aims to help students understand the physics model of interaction and force.

[Insert about here Figure 11]

Let us note that we deliberately chose the ping-pong ball, as the action of the hand that holds it under the water is clearly perceived, and the ball rises as soon as the hand releases it. We also chose to ask students to draw a ball-interactions diagram before asking them to draw the force vectors on the ball; this decision to ask for formal representations comes from the "semiotic registers" tool. Here again, these choices are at a fine granularity level of knowledge. 


\section{Example of student work in class}

In this activity (Figure 11) the students have to construct a rather large set of new theoretical elements of knowledge about the compensation of forces associated with a vector representation. This activity requires establishing relationships between theoretical statements and an easily observable situation in which the students' perception is involved: they have to hold a ping-ball motionless under water. This is the first time that a principle (Inertia principle) has been introduced in the physics teaching for these students (grade 10).

First, let us note that the situation of a ball held under water presents an initial difficulty; that of acknowledging that the Earth is still acting on the ball, even when the ball is under water. This difficulty has been observed in several classrooms with different teachers and some students are difficult to convince.

To illustrate the complex relations between the world of objects-events and the theory-model world, we will give three short extracts from the same study as in the activity presented above (Küçüközer, 2000). In the first extract, the students are working on the second part of question 1 (Figure 11) about the forces acting on the ball, after having correctly answered the first part. They have a difficult discussion on the orientations of the different forces, one of them (F) suggesting that the "force of the hand" is oriented upwards because if the hand releases the ball (a comment made prior to those in the extract), the ball rises and therefore the force has this upwards direction.

519 L $\quad[.$.$] the Earth attracts it [the ball] downwards and the water makes it go back up$

523 L the hand... no er I don't know why I said that [in 519] so the water oh yeah, yeah wait - the water upwards 


\section{A no}

This discussion continues and deals with the importance of the respective forces. After two minutes, L seems rather sure of his proposal and they have already agreed that the hand acts on the ball downwards.

$557 \quad \mathrm{~L} \quad$... 'it's upwards it's the water yeah'.....

566 F the water acts, and the Earth - is it downwards? Is it like that? No, the Earth is upwards...

567 L no, the Earth is downwards, not upwards - the Earth doesn't push the ball upwards

Then the two students work on question 2.

570 A Look at the next question - they ask how you explain why the ball stays motionless, it's that normally...

571 L $\quad$ yeah it's because it pulls downwards

572 A no look, wait, listen, look, why does it stays motionless, I think it's because there are two forces that are smaller there [shows his sheet with the force vectors exerted by the hand and by the Earth on the ball] that make the same force as the biggest [force vector exerted by the water on the ball]

This short extract shows two typical ways of "viewing" and interpreting the situation. L interprets it from the noticeable event of the situation; the hand that pulls the ball downwards and A starts from a noticeable point of the activity statement: motionless and relates it to their modelling of the situations in terms of forces. A, as in other situations, is deeply influenced by the teacher's requirements. We interpret this in terms of didactical contract; A tries to do what the teacher expects of him. At the same time, this contract could help him to use a theoretical approach.

The last extract takes place during the correction with the whole class. It shows how the teacher goes from the objects-events level to determine the forces (second part of question 1, Figure 11) to reasoning that comes from theory-model; the principle of inertia in this case. 
This extract is in fact an example of type 3 relationships from theories-models to objectsevents, illustrated in the next case. This shows that the two relationships between the two worlds cannot be really involved in an isolated way.

719 P well, they say that the principle of inertia allows you to...

720 St $\quad \ldots$

$721 \mathrm{~T}$ what allows you to say what you are saying, that the forces compensate each other (?)

722 St1 well, the forces compensate each other

723 St2 they compensate each other

$724 \mathrm{~T}$ can you read what it is in the model? [text given to the students before starting the activity stating the Inertial principle and the laws of mechanics]

729 F if the velocity of a system does not vary then all the forces that exert on the system compensate each other

$730 \mathrm{~T}$ That's it, the velocity does not vary because the system is motionless. So, since the velocity does not vary, the forces compensate each other; this justifies our diagram, in fact before drawing the diagram you have to look at the principle and then you work out the diagram ...

This type of reasoning involves recognising the status of a principle and, in fact, illustrates the next type of teaching activity, which aims to help students understand the relationships between theory-model and objects-events. This is a crucial aspect of understanding Newton's mechanics.

Activity involving the relationship between theory/model and objects and events (types 3 and 4)

The modelling choice has provided guidance to the designers for proposing such activities. The chosen activity given in Figure 12 is based on the model of interactions (Figures 8 and 4) introduced in part II, and the activity is at the beginning of part III (Figure 9). 
This activity aims to help students use the basic components of the concept of force; contact force and distance force: if two objects are not in contact (in this case, hand and ball) then there is no force between these objects; on the contrary, the air is in contact and acts on the ball while the Earth acts at a distance. This type of reasoning is not spontaneous; it is very likely that students will use the overall causality-force and force-motion relations (Table 1), and students have to learn it.

The activity was introduced several years after the first design of the entire sequence. A teacher who had not participated in the group that designed the sequence made the proposal after using the sequence in his class. The teacher was particularly interested in the history of science and attached importance to modelling; because of this, he suggested explaining two historical models to the students. The group accepted his proposal, although some members were reluctant because of the length of the sequence. In fact, one of the teachers who was reluctant at the time has now been using this activity in his class for two years, and recognizes that it "works very well with the students; the historical aspect removes their worries about their mistakes, and the activity allows students to review what they have learnt previously, particularly the modelling process."

\section{Activity to relate elements of the model (type 4)}

Such activities require that students have acquired at least a partial understanding of the model. This design is not easy because it often requires in-depth knowledge of the theory/model. It is therefore not surprising that, in the SESAMES sequence, these activities are at the end of a part and at the beginning of the next part. The activity illustrating the type 4 relationship was also designed several years after the first design; we do not have a specific 
analysis of it. The activity presented in Figure 13 is situated at the beginning of Part IV of the sequence and to work on it, the students have to use the laws of mechanics introduced in Part III.

[Insert about here Figure 13]

This activity leads the students to take into account the vector aspect of velocity and recognize that velocity has a constant magnitude but a varied direction (at grade 10, acceleration is not introduced). The activity should help students to develop their understanding of the relationship between force and velocity change by establishing links between the vector aspects and the natural language of the laws of mechanics. At this level, it is just an introduction to this basic relation. The sequence does aim to introduce a formal relation between force and change of velocity vectors. This acquisition was studied at grade 11 with a sequence designed by our group; it appeared that vector construction plays a major role in students' understanding of this fundamental relation (Küçüközer, 2005).

\section{Remarks on the levels of granularity of the design}

The Two-World theory and the specific choices guided the design of a teaching sequence on several levels. The structure of the sequence is influenced by the modelling approach; as has been discussed before, the SESAMES sequence starts with introducing action and then force, instead of the effects of force as is suggested by the official curriculum. The necessity of coherence between the theory/models proposed in the sequence and the set of material situations to be studied also affects the main structure of the sequence. This coherence is not easy to observe. In fact, in the first years after the initial design of the mechanics sequence, because of the official curriculum, friction forces were not included in the model of laws of 
mechanics. However, over the following years it clearly appeared that, for many exercises, the teachers had to introduce these forces as a particular case, but no general case for friction forces was introduced. The modelling guidance of coherence between the theory/model and the experimental field has led the designers to introduce friction forces in the model even though they were taking the risk of not observing the official curriculum.

\section{Design of the comments for teachers}

These comments are addressed to all teachers, to enable them to use the teaching sequences without having taken part in the design process. The teachers have direct access to the website PEGASE; usually they visit it after discussions with colleagues or after in-service professional development sessions. The comments have two main aims: (1) explaining our choices and the reasons for them and (2) helping teachers to "stage" the activity in their classrooms so that the types of knowledge (including skills, process of science) involved in the activity (from the designer's perspective) "live" in the classroom.

Two different types of comments have been designed; a series of comments are associated with specific components of a teaching sequence, and broader comments in the sense that they are relevant to all the teaching sequences based on the modelling approach of the SESAMES group.

\section{Comments associated with the mechanics teaching sequence}

On the PEGASE website (http://pegase.inrp.fr) each activity is presented in a window (for example Fig. 14) with five buttons giving access to comments for teachers: (1) Aim ("But"), (2) Preparation, (3) Knowledge; that is, comments on the knowledge to be taught and information on the physics content ("Savoir"), (4) Students' behaviour; that is, information on the students' behaviour and the way of taking their difficulties into account ("comportements des élèves”); (5) Providing answers (“Corrigé”). 
[Insert about here Figure 14]

The five headings (on each button) provide structure to the comments; a structure based on the teachers' experience, as distinguishing between aims, session preparation, knowledge, and providing answers are current practices in teachers' documents. However, the "students' behaviour" button has been introduced, together with a hypothesis on teachers' knowledge, because usually a teacher is unaware of the students' behaviour when they are working in small groups; this work is private and the students' comments are not made public (at least a part of them) at the class level. A teacher cannot follow a group's work during the whole activity. Our approach was therefore to show relevant examples of students' activity in order to improve the teacher's understanding of students' approaches, not just overall but also on specific aspects of knowledge. In fact, some teachers do not easily understand students' approaches during these "private" discussions (Saint Georges \& Richoux, 2005).

We will just give an example of the 'Knowledge' button ("savoir"). For the activity given in Figure 12 (relation from theory/model to objects/events), the comment is:

“[...] We have given up finding a situation which could convince students that this force (in the direction of the movement) was not necessary for the movement. We could only convince them with an argument such as: 'there was no force in the direction of the movement because there is no system that exerted it'. In this way, we use an argument from the taught model ( $a$ theoretical argument) to help students overcome their intuitive knowledge."

This type of comment illustrates the role of the modelling approach. In this case many studies show the students' difficulties in acquiring these elements of knowledge, so the designers considered that they should provide arguments to the students. However, experimental argument is difficult if not impossible (Koyre, 1990), so it was decided to provide an 
argument at the level of theory/model, and to help students develop the coherence of their understanding of theoretical knowledge. The situation is similar for the students' difficulties in the activity given in Figure 11 concerning the action of the Earth on a ping-pong ball held in water; theoretical arguments seem unavoidable.

The button "comportement des élèves" ('students' behaviour') has given teachers access to short video extracts with comments, showing specific students' difficulties such as in categorizing the Earth as an object.

\section{Broad comments based on modelling}

The aim of these broad comments is to propose elements that deal directly with the teacher's professional activity. These texts are structured with "markers". A marker works like a conspicuous signal for a teacher. These markers can be relevant to different categories of classroom situations and can help a teacher during different phases of his/her activity; during a preparation, in a laboratory, in a classroom, and also when s/he is correcting or writing a problem statement (http://pegase.inrp.fr/theme.php?Rubrique=2\&id_theme=30). These markers have a similar function to the "teachers' concerns" of the PEEL project (http://peelweb.org). The PEEL project (Erickson, Minnes Brandes, Mitchell \& Mitchell,. 2005) has similar characteristics as the SESAMES project in the sense that both have had a long history of producing teaching resources and a common aim born from teachers' concerns about students who rarely contribute ideas of their own. A major difference is that SESAMES is explicitly focused on science and we try to make our theoretical choices explicit. In any case, even with these differences, we face a similar problem concerning how to structure the resources that are not ours, is not discipline-dependent. At this stage of our research, our structuring has been influenced by the Two-Worlds theory but has also been adapted so as to be understood by teachers who do not know about the theory. Let us note that, for each activity, in the PEGASE 
window there is a list of links to the relevant markers (Figure 14 under the heading ‘ressources liées’ (linked resources).

Each marker has two parts: advantages and risks. Examples of markers are given to illustrate the necessity of introducing other criteria than those given by the modelling process to stage the activities in the classroom.

"Maker A" is directly associated with a type of activity presented above, activity type 1; relationships at the "objects and events" level. Its title is "students are not explicitly invited to refer to a model", which implies that students' activities deal mainly with description or interpretation without involving physics concepts. The proposed advantages are based on learning hypotheses: students do not know how to describe an experiment in a relevant physics way; they need to learn how. The risks are from the teachers' points of view: the teacher should not discredit this type of activity, thinking that it is too easy for students.

The three other markers correspond to activities in which the students use a model that they already know and discover a new model or are invited to construct a new element of a model, dealing with relationships 2, 3 and 4 (figure 7).

Marker B: "Activities in which students are invited to use some elements of a model that has already been introduced". These activities aim at developing links between theory/models and experimental fields in both directions.

Marker C: "In this type of activity, students discover a new element of a model at the end of the activity". These activities mainly aim at developing type-4 relationships, internal to theory/model, and relationships 2 and 3 between the experimental field in both directions.

Marker D: “Activities in which students are invited to use a new model from the beginning of the activity". Here, relationship 3 is mainly developed.

We do not give the complete text of each marker, we just comment that the markers deal with a difficult component of physics teaching; that is, the risk of arbitrariness when presenting an 
experiment and its interpretation without specifying the approximation and/ot the basic choices. For example, teachers are told to be careful when they generalize a model to its whole field of validity because generalizations can appear arbitrary to students and unsettle them.

The structure of the broad comments with "markers" is experience-based teaching. The idea is that a teacher should be aware of the potential difficulties of some types of situations. This idea entails that the teacher can recognize the type of situation and is aware of its specific characteristics, taking them into account in his/her behaviour. Up to now, these statements have been hypothetical and because they merely explain the problem, future research is necessary.

\section{Discussion}

To discuss our theoretical approach to designing of teaching sequences, we have compared it to another approach, recently published in "Model based learning and instruction in science" by Clement and Rea-Raminez (2008). In both cases, the design activity was initiated several years ago and has been carried out in collaboration with teachers.

In their introductive chapter, Rea-Raminez, Clement \& Nuñez-Oviedo (2008) present the same point of view as us regarding the role of grand theories on design: "Even though these theories [the grand theory of conceptual change] are extremely valuable, they are still quite general and do not provide a sufficient understanding of underlying mechanisms to give much guidance for curriculum development” (p.27).

In reference to the three poles of the didactical triangle, the knowledge pole in relation to students is essential in the theoretical framework of design in both cases.

The difference appears in the epistemological references. Clement et al (2008) refer to a “cognitive historical” approach, and Nersessian's work is a major reference (1992 among 
others). Instead, we use two types of references in the epistemology of science and in the epistemology of everyday knowledge that emphasize the social aspect of knowledge. When referring to the analysis of the cognitive processes of scientists as individuals in a community (for example Nersessian analysed Faraday's work and reconstructed the cognitive process), Clement et al. have transposed both the scientific knowledge process and the individual cognitive process to develop their curriculum. Clement and his colleagues have emphasized the role of analogy in their curriculum development, due to its importance in the scientist's work.

It is interesting to underline that Rea-Raminez, Clement \& Nuñez-Oviedo (2008) introduced the idea of types of knowledge (Table 3) and introduced two main distinctions between theories and observation and four types of knowledge, as we have done (Figure 7).

[Insert about here Table 3]

Clement et al.'s modelling process with four types of knowledge is, on the whole, similar to ours, as we have two main types of categories: theories and observations. The two types of theories are also in the theory model world. However, Rea-Raminez et al. include qualitative or mathematical descriptions including empirical laws in observation, like the behaviour of the relation pv=kt. In our study, we would have included these in the theory model, as the activities involve the recognising the behaviour of concepts like pressure, temperature and their relations, and this does not fit the level of description in terms of objects and events of the material world. From our point of view, this is an interpretation in terms of concepts. However, for physicists, the relation between pressure and the the state of a gas is obvious, and to them, variation of pressure is equivalent to gas behaviour, but for the students who are 
learning the concept of pressure, for example, it is a concept which does not describe the behaviour of gas (Givry, 2003).

Both groups have emphasized the idea of learning pathways with intermediary steps between students' initial knowledge and target knowledge. For Clement et al., the reference to conceptual change and the mental model (Gentner and Stevens, 1982 for example) plays a major role, and 'model' means either the scientist's or the learner's cognitive representation at a given time of teaching. This reference has led them to specify the episodes of students' dissatisfaction and revisions of their mental models. Their learning pathways are carefully defined at a fine grain size. They studied learning pathways in terms of evolution within the teaching time of explanatory models. Most importantly, they have taken analogy as a main factor for physics learning.

As for us, we have studied the learning pathway in terms of evolution of the elements of knowledge used by the learners in their oral/gesture/written production as related to teaching situations during the teaching sequence. Our main factor for physics learning is the distinction between theory and observation-perception of objects and events in order to make the links unavoidable in physics teaching.

These two approaches have led to different design tools and teaching sequences. The two explicit epistemological references on cognitive models, with the role of analogy and the process of conceptual change on the one hand, and the relations between theory-models and objects-events on the other hand, have influenced design on several levels. Clement \& al. proposed a cycle for each step in model evolution; the GEM cycle: Generate model, Evaluate Model, Modify Model (student contribution), Modify Model (teacher contribution). They also proposed making explicit goals and strategies at different time-scale levels for curriculum design and teaching (levels of several months, days, minutes, one hundred seconds and seconds). This shows that their design has been carried out on different scales and has 
included a fine grain size. In our design, our two-worlds modelling tool plays a similar role to the GEM cycle. It structures our designed teaching sequences and guides the design of teaching activities at a fine grain size. Clement $\&$ al. considered learning pathways as an evolution of mental models. We have considered them as an evolution of students' understanding of the relation between theoretical elements and experimental facts or observable events, and this has led us to attach importance to the language in the design, particularly on wording the teaching activities, the model and comments for teachers as well as, of course, in the classroom. Both approaches take into account a fine grain size. These two approaches contribute to design-based research in two main ways. Firstly, they show that different epistemological choices, which are really related to the design, lead to different teaching resources. These teaching resources can be efficient and therefore offer the teachers different possibilities according to their own preferences. Secondly, they allow debate on how the theoretical aspects that we call "specific theory" differ, which opens up scientific debate.

\section{Conclusion}

Regarding the role of theories in design activity, we have considered with Cobb \& al. (2003) that our theoretical framework is "accountable to the activity of design". The two-worlds framework is mainly constructed from grand theories on knowledge and learning. Moreover, we have made specific choices regarding teaching and learning and have devised three different new tools; 'knowledge distance', 'modelling relations' and 'semiotic registers', which can be used directly in designing teaching resources. These specific theories, specific choices and tools have guided the design process of the teaching sequences and the associated comments for teachers, as well as specific and broad teaching comments. However, professional experience is still involved in designing. Therefore this work of making the bases explicit for designing is only one step in a long process to obtain sharable specific theories such as those proposed by the design-based research collective (2003). It is clear that if the 
specific theory of Two Worlds is available, we do not have an elaborated specific theory for the teaching pole in relation with the knowledge and learning poles. However, this specific theory and the tools allow scientific debates on the following precise aspects: the specific theory itself, the way the tools are used, the craft knowledge involved in design and their roles in the refinement process. More research is necessary to investigate these aspects further.

\section{References}

Bachelard, S. (1979). Quelques aspects historiques des notions de modèle et de justification des modèles. In P. Delattre \& M. Thellier (Eds.), Elaboration et justification des modèles (Vol. 1, pp. 3-19). Paris: Maloine S.A.

Bannan-Ritland, B., \& Baek, J. Y. (2008). Investigating the act of design in design research: the road taken. In A. E. Kelly \& R. A. Lesh \& J. Y. Baek (Eds.), Handbook of design research methods in education. Innovations in science, technology, engineering, and mathematics learning and teaching. New York: Routledge.

Brousseau, G. (1998). Théorie des situations didactiques. Grenoble: La pensée sauvage.

Bunge, M. (1973). Method and matter. Derdrecht-Holland.: Reidel publishing company.

Buty, C., Tiberghien, A., \& Le Maréchal, J. F. (2004). Learning hypotheses and associated tools to design and to analyse teaching-learning sequences. International Journal of Science Education, 26(5), 579-604.

Chevallard, Y. (1991). La transposition didactique (2ème ed.). Grenoble: La Pensée Sauvage. Clement, J., \& Rea-Raminez, M. A. (Eds.). (2008). Model based learning and instruction in science. Dordrecht: Springer.

Cobb, P., Confrey, J., diSessa, A., Lehrer, R., \& Schouble, L. (2003). Design experiments in educational research. Educational Researcher, 32(1), 9-13. 
Cobb, P., Gresalfi, M., \& Hodge, L. L. (in press). An interpretive scheme for analyzing the identities that students develop in mathematics classrooms. Journal for Research in Mathematics Education

Coulaud, M. (2005). Evaluer la compréhension des concepts de mécanique chez des élèves de secondes : développement d'outils pour les enseignants. Thèse de doctorat, Université Lyon 2, Lyon.

diSessa, A. (2006). A history of conceptual change research: threads and fault lines. In K. Sawyer (Ed.), Cambridge handbook of the learning sciences (pp. 265-282). Cambridge, UK: Cambridge University Press.

Dumas-Carré, A., \& Weil-Barais, A. (Eds.). (1998). Tutelle et médiation dans l'enseignement scientifique. Paris/Berne: Peter Lang.

Duval, R. (1995). Sémiosis et pensée humaine, registres sémiotiques et apprentissage intellectuels [Semiosis and human thought, semiotic registers and intellectual learning]. Berne: Peter Lang.

Erickson, G., Minnes Brandes, G., Mitchell, I., \& Mitchell, J. (2005). Collaborative teacher learning: Findings from two professional development projects. Teaching and Teacher Education, 21(7), 787-798

Gaidioz, P., \& Tiberghien, A. (2003). Un outil d'enseignement privilégiant la modélisation. Bulletin de l'union des physiciens, 850, 71-83.

Gaidioz, P., Vince, J., \& Tiberghien, A. (2004). Aider l'élève à comprendre le fonctionnement de la physique et son articulation avec la vie quotidienne. Bulletin de l'union des physiciens, 866, 1029-1042.

Gentner, D., \& Stevens, A. L. (Eds.). (1983). Mental models. Hillsdale, NJ: Lawrence Erlbaum Associates. 
Giere, R. N. (1988). Explaining science. A cognitive approach. Chicago: The University of Chicago Press.

Givry, D. (2003). Étude de l'évolution des idées des élèves de seconde durant une séquence d'enseignement sur les gaz. Thèse, Université Lumière Lyon 2, Lyon.

Givry, D., \& Roth, W.-M. (2006). Toward a new conception of conceptions: Interplay of talk, gestures, and structures in the setting. Journal of Research in Science Teaching, 43(10), 1086-1109.

Guillaud, J.-C. (1998). Enseignement et apprentissage du concept de force en classe de troisième. Thèse, Université Joseph Fourier Grenoble 1, Grenoble.

Hacking, I. (1983/2005). Representing an Intervening. Cambridge: University Press Cambridge.

Jeannin, L. (2006). Appropriation par un enseignant de physique d'une nouvelle séquence d'enseignement : cas de la mécanique en seconde. Université Lyon 2, Lyon.

Koyré, A. (1990). Cohérence de la physique artistotélicienne. In Leçons de physique. Aristote (pp. 375-380). Paris: Presses pocket.

Küçüközer, A. (2000). Une compréhension de la notion d'interaction dans le cadre d'un enseignement de mécanique. Mémoire du DEA Didactiques et Interactions, Université Lumière - Lyon 2.

Küçüközer, A. (2005). L'étude de l'évolution de la compréhension conceptuelle des élèves avec un enseignement. Cas de la mécanique en 1ère $S$. Thèse, Université Lumière Lyon 2, Lyon.

Le Maréchal, J.-F., Barbe, E., Roux, M., Jean-Marie, O., Roue, B., \& Vincent, D. (2004a). Difficultés des élèves sur l'utilisation des ions dans le cadre des nouveaux programmes. Bulletin de l'Union des Professeurs de Physique et de Chimie, 98(867), 1399-1410. 
Le Maréchal, J.-F., Perrey, S., Roux, M., \& Jean-Marie, O. (2004b). Tableau d'avancement : avantages et difficultés au long de la scolarité. Bulletin de l'Union des Professeurs de Physique et de Chimie, 98(860), 93-100.

Leach, J., \& Scott, P. (2002). Designing and evaluating science teaching sequences: an approach drawing upon the concept of learning demand and a social constructivist perspective on learning. Studies in science education, 38, 115-142.

Levy-Strauss, C. (1962). La Pensée Sauvage. Paris: Plon Collection Agora.

Lijnse, P. (2000). Didactics of science: the forgotten dimension in science education research? In R. Millar, J. Leach \& J. Osborne (Eds.), Improving science education (pp. 308-326). Buckingham: Open University Press.

Lopes, J. B., Silva, A. A., Cravino, J. P., Costa, N., Marques, L., \& Campos, C. (2008). Transversal Traits in Science Education Research Relevant for Teaching and Research: A Meta-interpretative Study Journal of Research in Science Teaching, 47(5), 574-599.

Malkoun, L. (2007). De la caractérisation des pratiques de classes de physique à leur relation aux performances des élèves: étude de cas en France et au Liban. Thèse de Doctorat, Université Lyon 2 / Université libanaise, Lyon/Beyrouth.

Malkoun, L., Vince, J., \& Tiberghien, A. (2007, 17, 18, 19 octobre 2007). Relations entre pratiques d'enseignement de la physique au lycée et performances des élèves : cas de l'enseignement de la mécanique. Paper presented at the Cinquièmes Rencontres scientifiques de l'ARDIST La Grande Motte.

Méheut, M., \& Psillos, D. (2004). Editorial - Teaching-learning sequences: aims and tools for science education research. International Journal of Science Education, 26(5), 515-535.

Mercier, A., Schauber-Leoni, M. L., \& Sensevy, G. (2002). Vers une didactique comparée. Revue Française de Pédagogie, 141, 5-16. 
Mortimer, E., \& Scott, P. (2000). Analysing discourse in the science classroom. In R. Millar, J. Leach \& J. Osborne (Eds.), Improving science education: the contribution of research (pp. 126-142). Buckingham UK: Open University Press.

Nersessian, N. (1992). How do scientists think? Capturing the dynamics of conceptual change in science. In R. N. Giere (Ed.), Cognitive models of science (Vol. 15, pp. 3-44). Minneapolis: University of Minnesota Press.

Niedderer, H., Budde, M., Givry, D., Psillos, D., \& Tiberghien, A. (2007). Learning process studies. In R. Pintó \& D. Couso (Eds.), ESERA Selected Contributions book. (pp. 159171). Berlin: Springer.

Pegase: pegase.inrp.fr last consultation: March 2007.

Piaget, J., \& Garcia, R. (1971). Les explications causales. Paris: Presses Universitaires de France.

Psillos, D., \& Kariotoglou, P. (1999). Teaching fluids: Intended knowledge and students? Actual conceptual evolution. International Journal of Science Education, 21(1), 1738.

Rea-Raminez, M. A., Clement, J., \& Nùñez-Oviedo, M. C. (2008). An instructional model derived from model construction and criticism theory. In J. Clement \& M. A. ReaRaminez (Eds.), Model based learning and instruction in science (pp. 23-43). Dordrecht: Springer.

Saint-Georges M., Richoux H. (2005). Utiliser en formation des vidéos d'élèves ; Quels apports pour les enseignants ? Communication aux $4^{\text {ème }}$ rencontres de l'ARDIST, Lyon. Retrieved June 17, 2007, from http://www.inrp.fr/ardist2005/recherche.php

Saxe, R., \& Carey, S. (2006). The perception of causality in infancy. Acta psychologica, 123 (1-2), 144-165.

Scott, P. (1992). Pathways in learning science: a case study of the development of one 
student's ideas relating to the structure of matter. In R. Duit \& F. Goldberg \& H. Niedderer (Eds.), Research in Physics Learning: theoretical issues and empirical studies (pp. 203-224). Kiel: I.P.N.

Sensevy, G. (2007). Des catégories pour décrire et comprendre l'action didactique. In G. Sensevy \& A. Mercier (Eds.), Agir ensemble : Eléments de théorisation de l'action conjointe du professeur et des élèves (pp. 13-49). Rennes: Presses Universitaires de Rennes (PUR).

Sensevy, G., Tiberghien, A., Santini, J., Laube, S., \& Griggs, P. (2008). An epistemological approach to modeling: Cases studies and implications for science teaching. Science Education, 92(3), 424-446.

Spelke, E. S., Phillips, A., \& Woodward, A. L. (1995). Infants' knowledge of object motion and human action. In D. Sperber \& D. Premack \& A. Premack (Eds.), Causal Cognition: A multidisciplinary debate (pp. 44-78). Oxford: Clarendon Press.

The Design-Based Research Collective. (2003). Design-Based Research: An emerging paradigm for educational inquiry. Educational Researcher, 32(1), 5-8.

Tiberghien, A. (1980). Modes and conditions of learning: An example: Learning of some aspects of the concept of heat. In W. F. Archenhold \& R. Driver \& A. Orton \& C. Wood-Robinson (Eds.), Cognitive development research in science and mathematics, Proceedings of an international seminar (pp. 288-309). Leeds: University of Leeds.

Tiberghien, A. (2000). Designing teaching situations in the secondary school. In R. Millar, J. Leach \& J. Osborne (Eds.), Improving science education: The contribution of research (pp. 27-47). Buckingham, UK: Open University Press.

Tiberghien, A., Veillard, L., Le Maréchal, J.-F., Buty, C., \& Millar, R. H. (2001). An analysis of labwork tasks used in science teaching at upper secondary school and university levels in several European countries. Science Education, 85(5), 483-508. 
Tiberghien, A. (2004). Causalité dans l'apprentissage des sciences. Intellectica, 38(1), 69102.

Viennot, L. (1996). Raisonner en physique. La part du sens commun. Bruxelles: De Boeck.

Viennot, L., \& Rainson, S. (1999). Design and evaluation of a research-based teaching sequence: The superposition of electric field. International Journal of Science Education, 21(1), 1-16.

Vosniadou, S., \& Brewer, W. F. (1992). Mental models of the earth: A study of conceptual change in childhood. Cognitive Psychology, 24, 535-585.

Vygotski, L. S. (1934/1997). Pensée et langage (3ème ed.). Paris: La Dispute.

Wertsch, J. V. (1985). La médiation sémiotique et la vie mentale : L.S. Vygotsky et M.M.

Bakhtine. In B. Schneuwly \& J. P. Bronckart (Eds.), Vygoski aujourd'hui (pp. 139-168). Paris: Delachaux et Niestlé. 
Figure 1a

Grand theories: ?

Grand theories: Ecology of K

Grand theories: ?

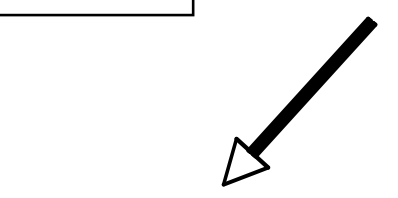
Specific theory:?

Specific theory: ?

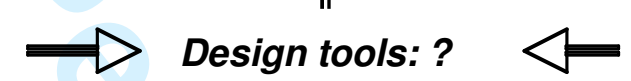

Grand theories: ?

Design tools: ?

Design tools: ?

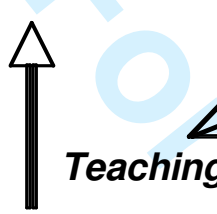

Figure 1b

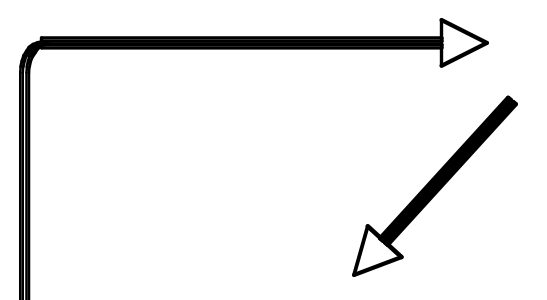

Epistemology (modelling)

Specific choices on design

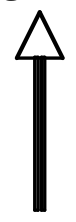

Teaching

Grand theories: Joint action theory and ecology of $\mathrm{K}$ No Specific theory but specific choices on design

\section{Specific theory: Two worlds}

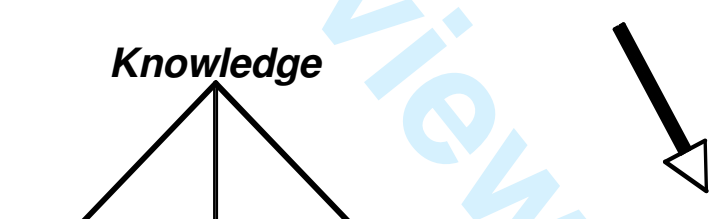

Design tools:

Distance K

Modelling Relation

Semiotic registers

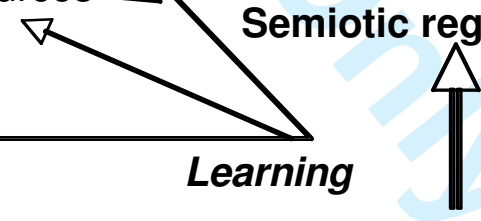

Grand theories: Socioconstructivism, Vygotski Learning involves N̦mall elements of knowledgeÓ Specific theory: introduced in the two worlds theory

Figure 1: Global structure of the theoretical framework going from grand theories to specific theories and tools to design resources. Figure 1a: general case; figure 1b: our choices and construction. The double line corresponds to the development and use of specific theories and tools 
1

2

3

4

5

6

7

8

9

10

11

12

13

14

15

16

17

18

19

20

21

22

23

24

25

26

27

28

29

30

31

32

33

34

35

36

37

38

39

40

41

42

43

44

45

46

47

48

49

50

51

52

53

54

55

56

57

58

59

60

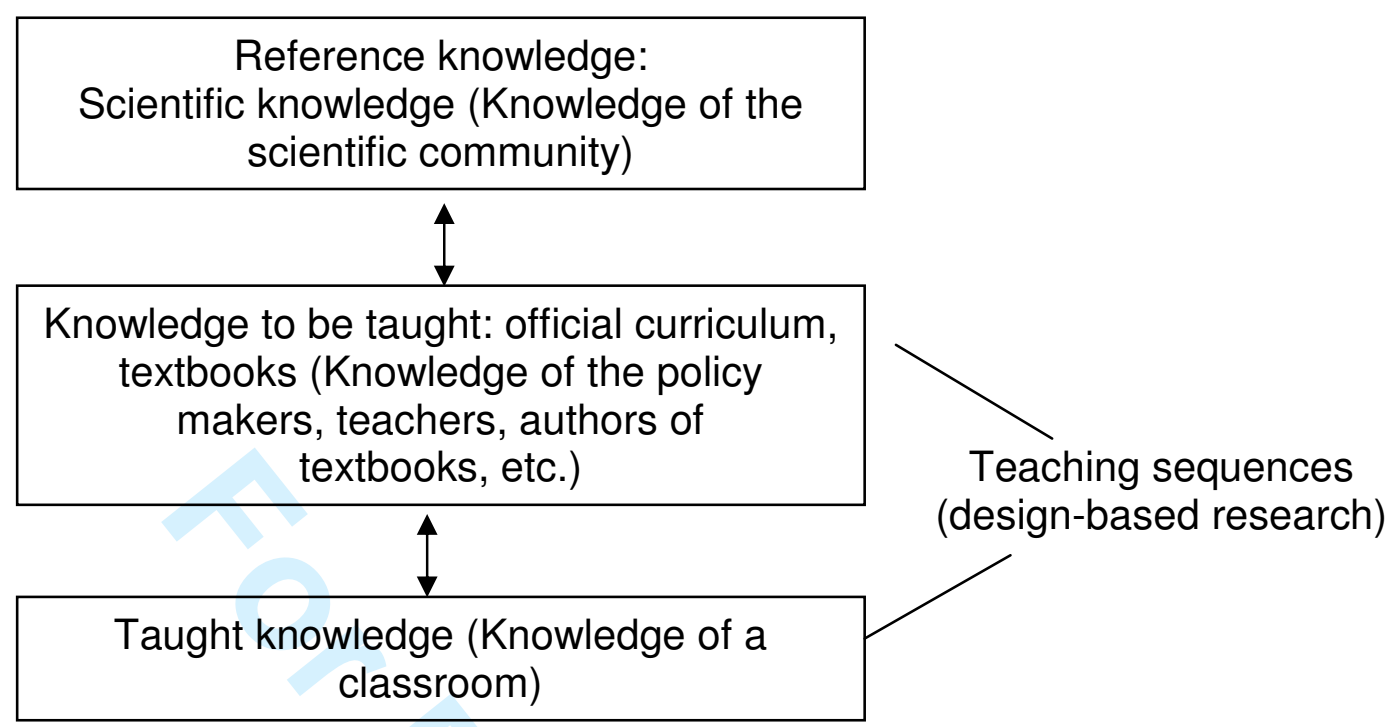

Figure 2: Place of a teaching sequence produced in a design-based research activity in the transposition process 


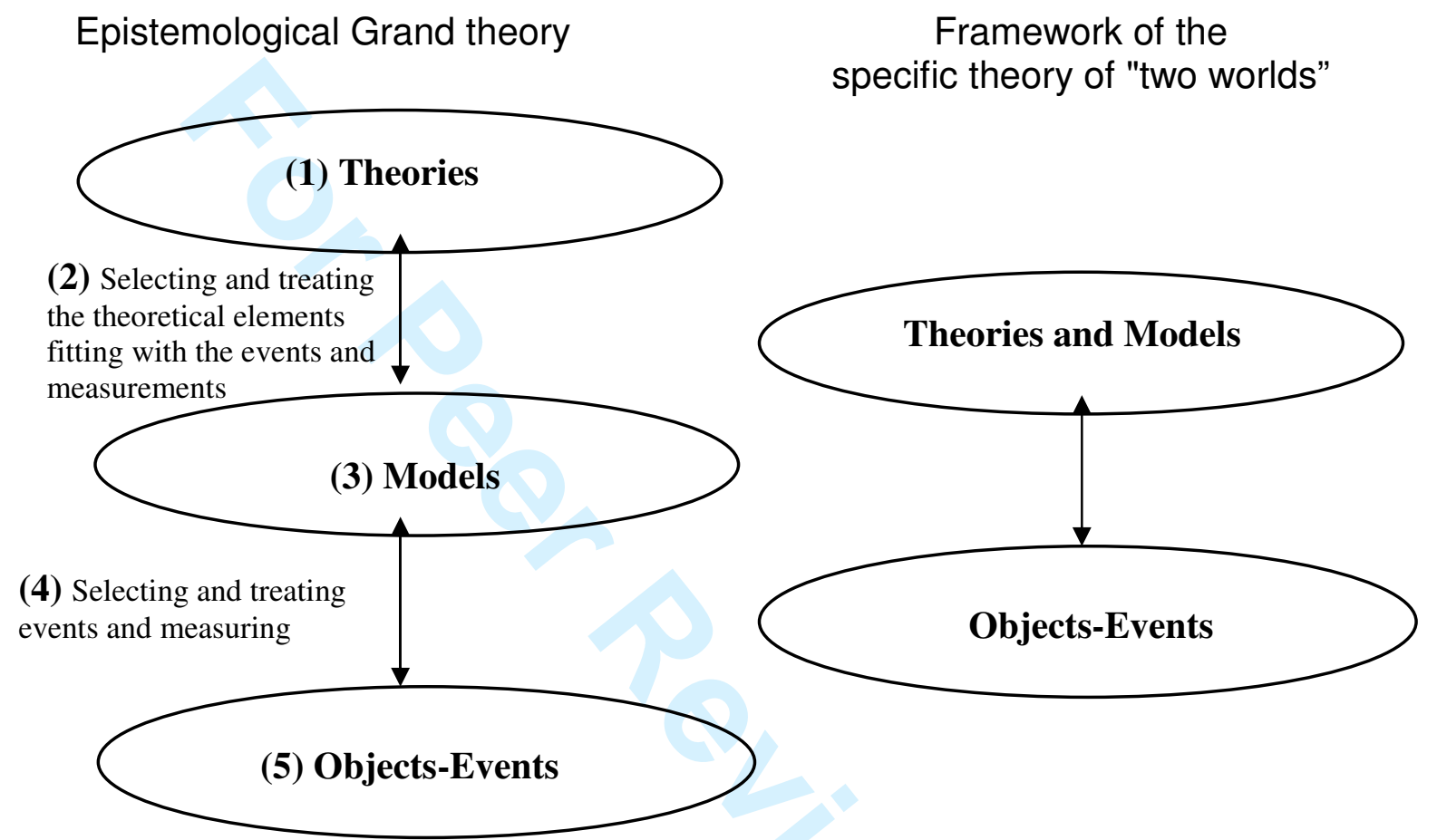

Figure 3: Transposition from our epistemological analysis of physics in terms of modelling, to the framework of the Two-Worlds specific theory for designing teaching sequences at secondary school level 
1. When a system $\mathrm{X}$ is in interaction with a system $\mathrm{A}$, the action from $\mathrm{A}$ on $\mathrm{X}$ is called force exerted by $\mathrm{A}$ on $\mathrm{X}$

2. To represent a force on a system, the system on which the force is exerted is represented by its centre of gravity to which the mass of the system is attributed.

3. The force exerted by A on X is represented by a vector with a symbol (see Figure). Its characteristics are as follows:

4. its origin is the point representing the system;

5. it goes in the direction of the force;

6. its length is proportional to the value of the force (called magnitude)

7. the value of the force is expressed in Newton (symbol: $\mathrm{N}$ ).

8. When two systems $\mathrm{A}$ and $\mathrm{X}$ are in interaction, the force exerted by $\mathrm{A}$ on $\mathrm{X}$ and the force exerted by $\mathrm{X}$ on $\mathrm{A}$ have the same magnitude and are opposite in direction.

9. An interaction is modelled by two forces which, for all situations and in all cases, have same magnitude and opposite directions. The vectors which represent forces are on the same straight line; this straight line depends on the situation being studied.
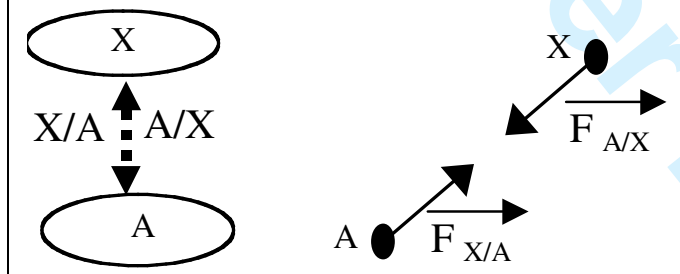

Figure 4: Extract of a text given to students in the mechanics teaching sequence. The lines are numbered for reference in the comments 


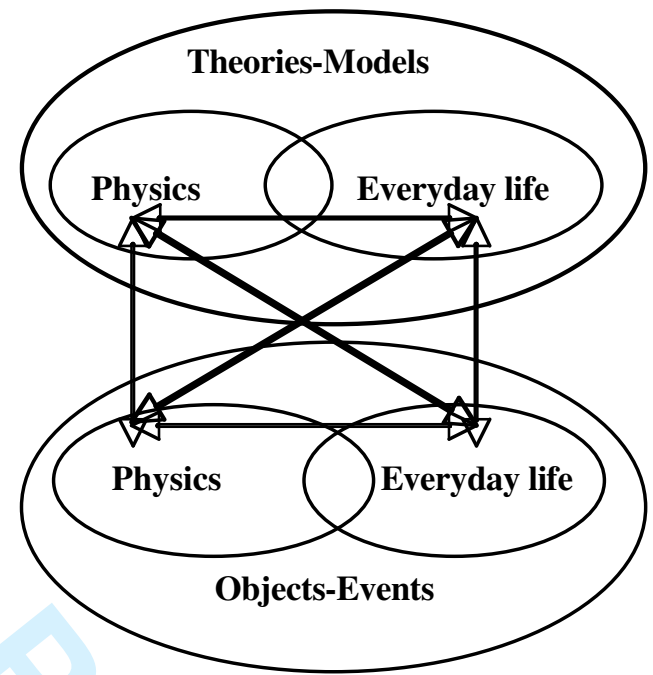

Figure 5: Representation of the specific theory of the 'Two Worlds' with the double categorization of knowledge: (1) modelling between the objects/events and the theories/models and (2) everyday/physics knowledge 


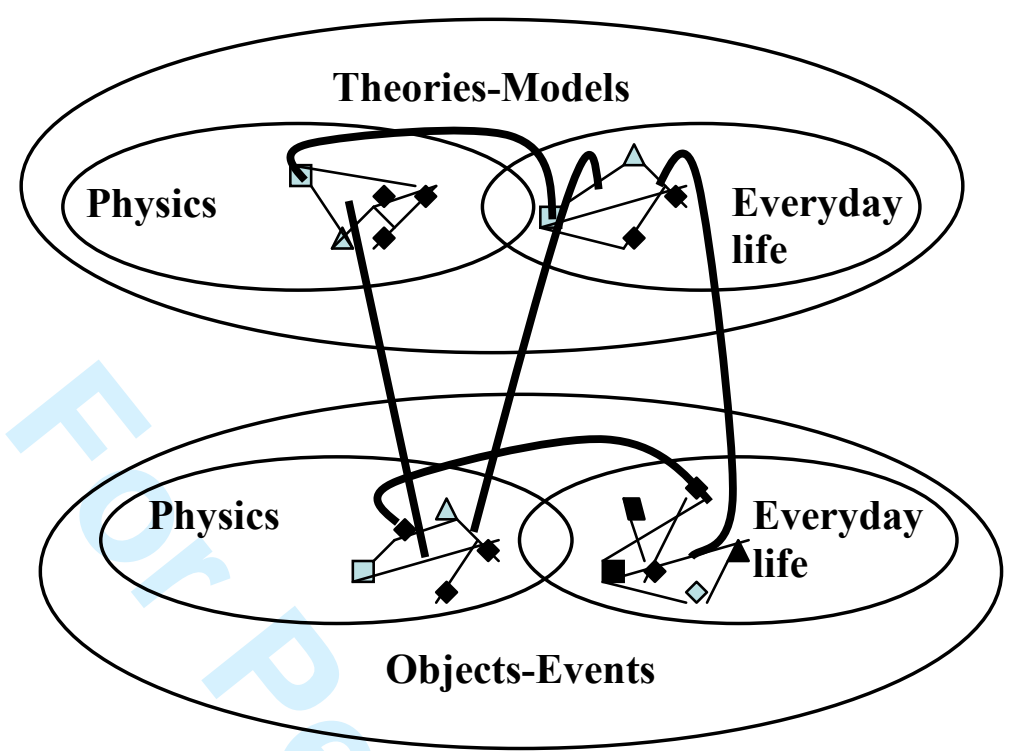

Figure 6: Image illustrating our learning choices in the specific theory of the "Two Worlds". The thick curved lines illustrate some of the new relations constructed by the learner, and the rest of the figure represents the taught knowledge 
Theories and models

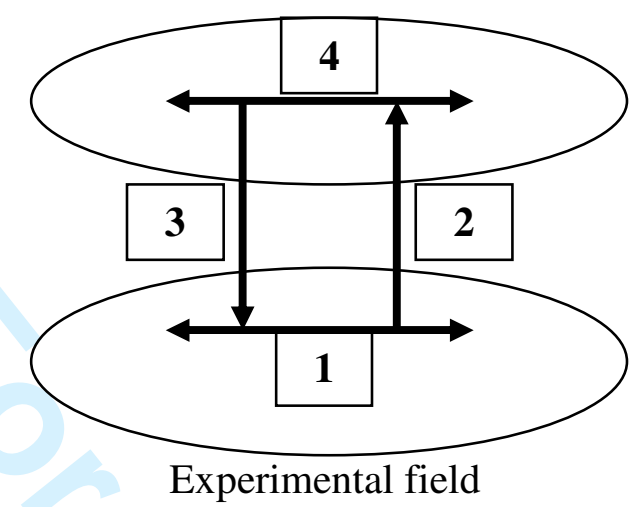

Figure 7: Modelling relations tool from the specific theory of the Two Worlds 


\section{First part of the model of interactions}

A system is a (material) object, part of an object, or a set of objects (this way of dividing reality is a choice made by the person who studies the situation).

Interactions: when system $A$ acts on system $B$, simultaneously $B$ acts on $A$; we say that $A$ and $B$ are in interaction. The action of $\mathrm{A}$ on $\mathrm{B}$ is written as $\mathrm{A} / \mathrm{B}$ and the action of $\mathrm{B}$ on $\mathrm{A}$ is written as $\mathrm{B} / \mathrm{A}$.

This statement is applicable in all situations, both when the systems are motionless and when they move.

\section{Representation}

Representation of a system

Representation of a contact interaction

Representation of a distance interaction

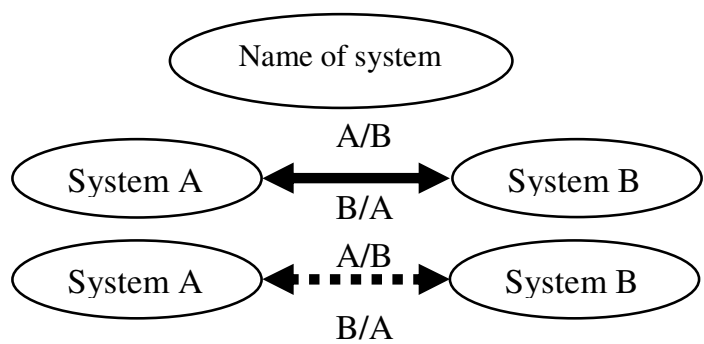

System B

As soon as the system is chosen, only its interactions with the other systems have to be taken into account (outside systems), the interactions inside the system are not relevant.

These interactions are represented with the other systems on the same schema. This schema is called a systeminteraction diagram. To clearly distinguish the chosen system from the other systems, its name is underlined in the diagram.

\section{Second part of the model of interactions}

(see Figure 4)

Figure 8: First part of the model of interaction introducing force 


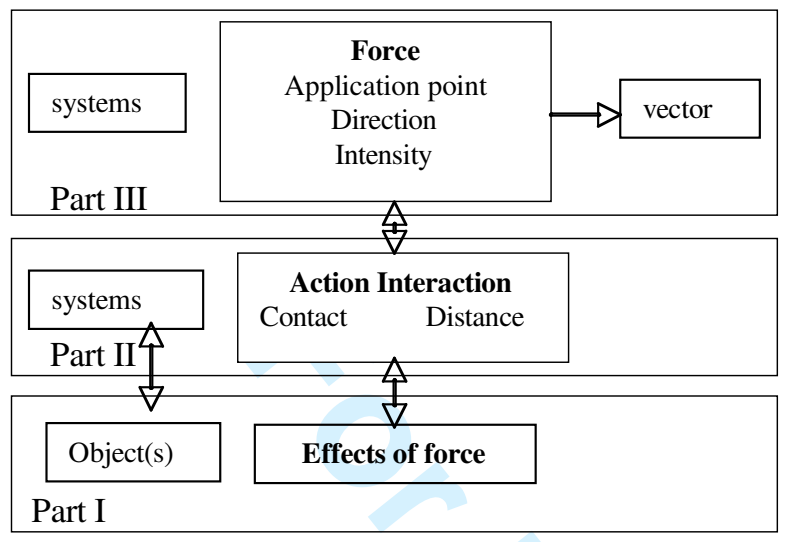

Official curriculum
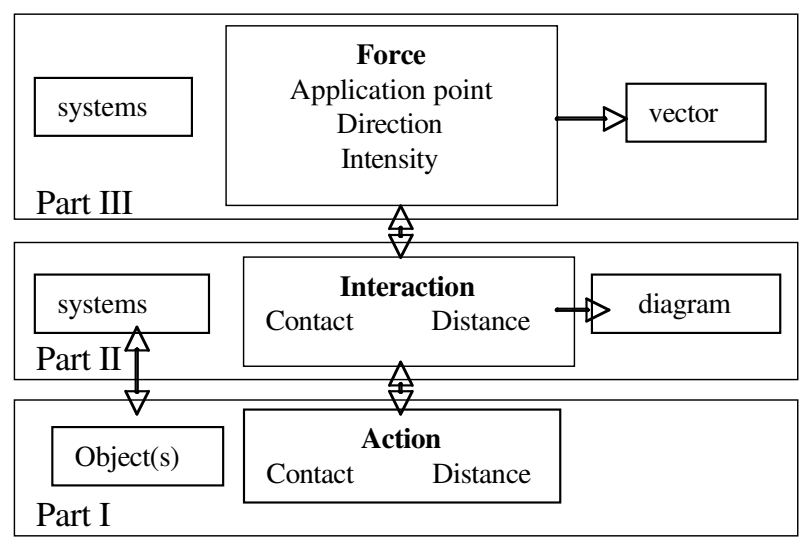

Sesames sequence

Figure 9: Structure of the official curriculum and the SESAMES sequence for the introduction of dynamics 


\section{Part II Interactions and forces Activity 1: Introducing the notion of action}

You have at your disposal: a support, an elastic string, a stone.

The stone is hanging from an elastic string. It is motionless.

Questions

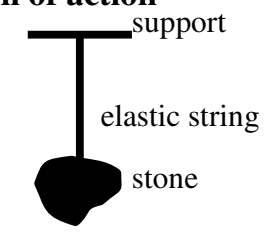

a) What are the objects which act on the stone?

b) On what objects does the stone act?

Figure 10: Activity statement aiming to help students describe a situation in terms of objects and events in a way which is relevant to interpretation in physics 
Part III, the Inertia Principle and other laws of mechanics Activity 2: Introduction to the laws of mechanics A ping-pong ball held by hand under water is motionless.

1) With the help of the model of interactions (parts I and II, [see Figure 4]) and of the laws of mechanics, draw: - a ball - interactions diagram

- a diagram of all the forces acting on the system ball

2) Again using the model, how do you explain why the ball remains motionless?

Figure 11: Activity statement aiming to help students to relate objects-events to theory-model 


\section{Part III, Inertia Principle and other laws of mechanics Activity 1: "Aristotle or Galileo"}

We want to analyse different students' answers to the question: "represent the forces which are exerted on the medicine-ball (when it is moving upwards) represented by a dot and labelled as M-B)". Two types of answers have been distinguished:

Students Group A

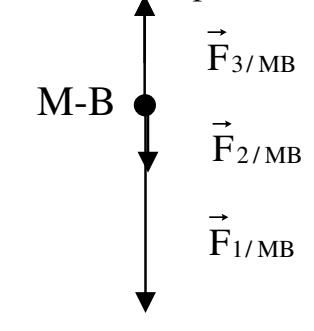

\author{
Students Group B
}

M-B

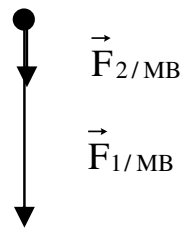

- 2 Using the information given at the beginning [a medicine-ball is thrown vertically upwards, the study focuses on the ball's upward motion], identify which Group (A or B) has analysed the situation intuitively.

- 3 a- Identify the systems 1 and 2 (present in the two representations) which act on the system MB. In your opinion, what does the force represent for Group A? Why did they need to represent this force?

b- With the help of the interaction model, justify the fact that this force does not model an action exerted by the medicine-ball when it moves upwards

Figure 12: Part of an activity statement (questions 2 and 3) aiming to help students relate elements of model to a material situation 


\section{Part IV. Universal gravitation Activity 1: Motion of the Moon}

To study the motion of the Moon around the Earth, we choose to represent it by its centre and we consider that this point has a circular motion.

When the gravity centre of an object has a uniform circular motion, we state that this object has a uniform circular motion. We study systems which, like the Moon, have a uniform circular motion.

1. Using the model of the laws of mechanics, say whether the forces exerted on a system like this (i.e. with a uniform circular motion) balance each other.

Figure 13: Activity statement aiming to help students relate elements of the model 
Figure 14. Window of the PEGASE website, giving the text of an activity (see translation in Figure 10) with five buttons of comments for teachers and links to relevant transversal 'markers' (balises in French)|

$165 \times 116 \mathrm{~mm}(300 \times 300$ DPI $)$ 
Action - Force (without and with motion)

2 worlds (Theory/model, objects/events)

An object is represented by a point, its trajectory by a line; and its mean
Students' knowledge

physics knowledge

\begin{tabular}{|c|c|c|c|}
\hline Theory/Model & $\begin{array}{l}\text { Velocity } \\
\text { Uniform and non }\end{array}$ & "Causality - Force" & $\begin{array}{l}\text { Interactions } \\
\text { Force exerted by Sys A on }\end{array}$ \\
\hline
\end{tabular}

uniform motion

These concepts are taught just before the introduction of force (grade 10); assessments suggest that they are at least partially understood by students. velocity by the ratio of the distance between two positions of the point to the time taken to travel between them Again, assessments suggest that students readily grasp the notion of mean velocity

Situations with different

Situations: great variety motions

In physics, motionless situations are not treated as special cases; rather, they are particular situations where $v=0$ on $a$ continuum
Sys B

Laws of mechanics

Action of one object on the other (without and with motion) and the reverse if contact between objects or at distance (Earth)

Table 1: Design tool: "knowledge distance" in the case of action and force 


\section{Progression in time of a task Time}

\begin{tabular}{|c|c|c|c|c|c|c|c|}
\hline $\begin{array}{l}\text { Sesames } \\
\text { sequence }\end{array}$ & $\begin{array}{l}\text { Teacher's } \\
\text { introduc- } \\
\text { tion }\end{array}$ & \multicolumn{2}{|c|}{ Small group work } & $\leftarrow$ & \multicolumn{3}{|c|}{$\begin{array}{l}\text { Classroom discussion, } \\
\text { correction, } \\
\text { Institutionalisation }\end{array}$} \\
\hline $\begin{array}{l}\text { Usual physics } \\
\text { teaching } \\
\text { Lecture } \\
\end{array}$ & \multicolumn{2}{|c|}{$\begin{array}{l}\text { Teacher's lecture } \\
\text { Institutionalisation }\end{array}$} & $\underset{\rightarrow}{\text { Classroom discussion }}$ & \multicolumn{4}{|c|}{$\begin{array}{l}\text { Teacher's lecture } \\
\text { Institutionalisation }\end{array}$} \\
\hline $\begin{array}{l}\text { Laboratory } \\
\text { activity }\end{array}$ & $\begin{array}{l}\text { Teacher's } \\
\text { introduc- } \\
\text { tion }\end{array}$ & Small & work & & $\leftarrow$ & $\rightarrow$ & $\begin{array}{r}\text { Possible } \\
\text { Classroom } \\
\text { discussion }\end{array}$ \\
\hline
\end{tabular}




\begin{tabular}{|r|r|r|}
\hline & Types of knowledge & Example: study of gases \\
\hline Theories & 4. Formal theoretical principles & Principles of thermodynamics \\
\cline { 2 - 3 } & 3. Explanatory models & Colliding elastic particle model \\
\hline Observations & $\begin{array}{r}\text { 2. Qualitative or mathematical } \\
\text { pvekt } \\
\text { descriptions of patterns in observations } \\
\text { including empirical laws }\end{array}$ & $\begin{array}{r}\text { (refers to observations of measuring } \\
\text { apparatus) }\end{array}$ \\
\cline { 2 - 3 } & 1. Primary-level data: observations & $\begin{array}{r}\text { Measurement of a single pressure } \\
\text { change in a heated gas }\end{array}$ \\
\hline
\end{tabular}

Table 3: Four types of knowledge used in science (Rea-Raminez et al. 2008, p.29) 